\title{
The Cell Wall of Bacillus subtilis
}

\author{
Danae Morales Angeles ${ }^{1}$ and Dirk-Jan Scheffers* \\ Department of Molecular Microbiology, Groningen Biomolecular Sciences and \\ Biotechnology Institute, University of Groningen, Groningen, The Netherlands \\ ${ }^{1}$ Present address: Faculty of Chemistry, Biotechnology and Food Science, \\ Norwegian University of Life Sciences, 1432, Ås, Norway. \\ *Correspondence: d.j.scheffers@rug.nl
}

DOI: https://doi.org/10.21775/cimb.041.539

\begin{abstract}
The cell wall of Bacillus subtilis is a rigid structure on the outside of the cell that forms the first barrier between the bacterium and the environment, and at the same time maintains cell shape and withstands the pressure generated by the cell's turgor. In this review, the chemical composition of peptidoglycan, teichoic and teichuronic acids, the polymers that comprise the cell wall, and the biosynthetic pathways involved in their synthesis will be discussed, as well as the architecture of the cell wall. $B$. subtilis has been the first bacterium for which the role of an actin-like cytoskeleton in cell shape determination and peptidoglycan synthesis was identified and for which the entire set of peptidoglycan synthesizing enzymes has been localised. The role of the cytoskeleton in shape generation and maintenance will be discussed and results from other model organisms will be compared to what is known for $B$. subtilis. Finally, outstanding questions in the field of cell wall synthesis will be discussed.
\end{abstract}

\section{Introduction}

The cell wall is a critical structural component of each bacterial cell, except for those few bacteria that lack a cell wall (Mollicutes). It determines bacterial cell shape and bears the stress generated by the intracellular pressure, called turgor. The integrity of the cell wall is of critical importance to cell viability. In both Grampositive and Gram-negative bacteria, the scaffold of the cell wall consists of the cross-linked polymer peptidoglycan (PG). In Gram-negative bacteria the cell wall lies in the periplasmic space, between the inner and the outer membrane of the cell, and consists of only 1 to 3 layers of PG. Gram-positive bacteria, like Bacillus subtilis, lack an outer membrane and so the cell wall constitutes the contact area with the external milieu (Figure 1). The Gram-positive cell wall contains 10 to 30 layers of PG, as well as covalently linked teichoic and teichuronic acid polymers 
A

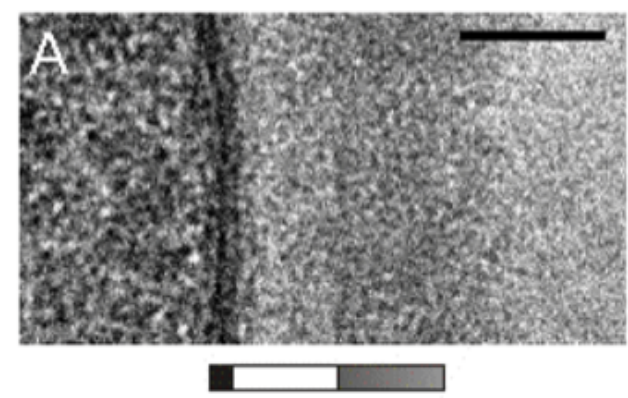

B
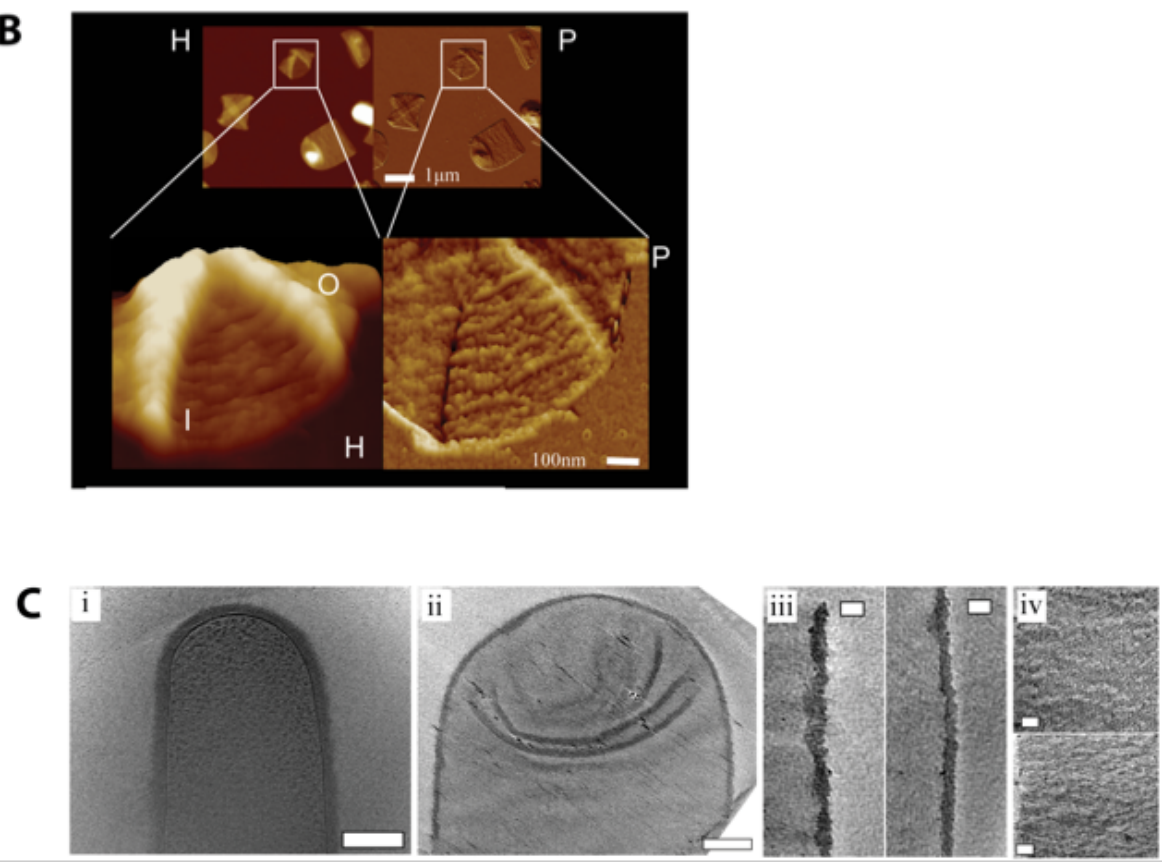

Figure 1. Cell wall architecture studied by various microscopy techniques (A) High magnification images of cell walls from frozen hydrated cells of Bacillus subtilis. The bars below the images indicate the different structures observed: black: cytoplasmic membrane; white: the Inner Wall Zone (IWZ), the Gram positive equivalent of the periplasm; grey: the Outer Wall Zone containing the bacterial cell wall. Scale bar: $50 \mathrm{~nm}$. Reprinted, with permission from ASM, from (Matias and Beveridge, 2006). (B) PG architecture of $B$. subtilis. AFM height $(H)$ and phase $(P)$ images of purified PG sacculi from broken $B$. subtilis cells. In the enlarged portions a cabling pattern is visible on the inside (I) surface of the sacculi, not on the outside (0). Scale bar 1 $\mu \mathrm{m}$. Reprinted, with permission, from (Hayhurst et al., 2008). (C) PG studied by cryo-tomography reveals that is PG density and texture is homogenous in cross-sections of both intact cells and purified sacculi. (i) Tomographic slice through a $B$. subtilis $\triangle$ ponA mutant (a mutant that is thinner than wild-type $B$. subtilis and thus amenable to ECT). Scale bar, $200 \mathrm{~nm}$. (ii) Tomographic slice through an isolated wild-type B. subtilis sacculus. Scale bar, $250 \mathrm{~nm}$. (iii) Two representative tomographic cross-sections across the wall of isolated $B$. subtilis sacculi perpendicular to the viewing plane reveal a globally straight sacculus side-wall with local variations in thickness. In both tomographic slices the sacculus interior is to the left. (iv) Two representative top-down slices through tomograms parallel to the plane of the sacculus illustrating surface textures (red arrows) previously interpreted to be the surfaces of coiled cables composed of helical coils of peptidoglycan. In both tomography slices the long axis of the cell runs vertically. Scale bars $50 \mathrm{~nm}$. Reprinted, with permission, from (Beeby et al., 2013). 
and attached proteins. For a long time, Gram-positive bacteria were thought not to contain a region comparable to the periplasmic space in Gram-negative bacteria, because ultrastructural studies on the Gram-positive envelope showed the cell wall in close apposition to the cytoplasmic membrane. Matias and Beveridge have revealed the existence of a periplasmic space in both $B$. subtilis and Staphylococcus aureus, using cryo-electron microscopy on frozen-hydrated bacteria (Figure 1; Matias and Beveridge, 2005, 2006). The existence of such a space would provide Gram-positives with the opportunity to move enzymes and solutes within a confined region, but without these having to be in direct contact with either the plasma membrane or the highly negatively charged polymers in the cell wall (Matias and Beveridge, 2005). Fractionation studies also provide evidence for the existence of a functional homologue of a periplasmic space in $B$. subtilis (Merchante et al., 1995). Similar techniques have also been used to identify novel bacterial structures, such as an outer membrane in the Grampositive Mycobacteria (Hoffmann et al., 2008; Zuber et al., 2008).

The discovery of an actin-like cytoskeleton in B. subtilis (Jones et al., 2001) and its role in synthesis of the cell wall (Daniel and Errington, 2003) have sparked a renewed effort to understand cell wall growth and shape determination in Bacillus as well as in other bacteria. Fluorescence microscopy techniques have made it possible to study the localisation of enzymes involved in cell wall synthesis in growing cells, as well as to look at localisation of newly incorporated PG in live cells (see Scheffers and Pinho, 2005). More recently, the development of fluorescent D-amino acid analogues (FDAAs) and click chemistry has made it possible to track cell wall synthesis (Kuru et al., 2012) and furthermore, to visualize cell walls in organisms such as Chlamydia and Planctomycetes that for a long time were thought to be lacking a cell wall (Jeske et al., 2015; Liechti et al., 2014; Pilhofer et al., 2013; van Teeseling et al., 2015). Electron cryotomography (ECT), pioneered by Grant Jensen and co-workers, has enabled us, for the first time, to see bacterial cytoskeletal elements in situ without any additional labelling technique (see Knowles et al., 2009) and has also allowed visualization of PG in B. subtilis (Khanna et al., 2019; Tocheva et al., 2013). Atomic Force Microscopy (AFM) has been succesfully used to study cell wall architecture in $B$. subtilis (Hayhurst et al., 2008) and several other organisms (below).

In this review, the chemical composition, architecture and synthesis of the cell wall of $B$. subtilis will be discussed. We will address how new findings have deepened our understanding of bacterial cell wall synthesis, but simultaneously have uncovered discrepancies in classical models of PG synthesis and have raised many new questions about the way bacteria grow.

\section{Cell wall structure and composition}

The two major structural components of the Gram-positive cell wall are peptidoglycan and anionic polymers that are covalently attached to PG or that are linked to the cytoplasmic membrane via acyl chain membrane anchors. Fractionation studies have revealed that about $9.8 \%$ of the total protein content of $B$. subtilis cells consists of periplasmic/wall associated proteins (Merchante et al., 1995), and a further proteomic analysis identified 11 protein that are bound to the 
cell wall (Antelmann et al., 2002), such as the wall associated protein A (WapA) that functions in intercellular competition (Koskiniemi et al., 2013), a wall associated protease (WprA) and several autolysins that are involved in wall turnover (discussed below). Not much is known about the role of these proteins in $B$. subtilis, for a review on protein sorting to the cell wall of Gram-positives see (Schneewind and Missiakas, 2014; Siegel et al., 2017).

\section{Peptidoglycan}

Peptidoglycan (PG), also called murein, is a polymer that consists of long glycan chains that are cross-linked via flexible peptide bridges to form a strong but elastic structure that protects the underlying protoplast from lysing due to the high internal osmotic pressure. The basic PG architecture is shared between all eubacteria that contain a cell wall (e.g. like all Mollicutes, Mycoplasma lack a cell wall). The glycan chains are built up of alternating, $\beta-1,4$-linked, Nacetylglucosamine (GlcNAc) and $\mathrm{N}$-acetylmuramic acid (MurNAc) subunits. An average glycan chain length for $B$. subtilis of 54 to 96 disaccharide (DS) units as determined by Ward using differential sodium borohydride labeling has been cited as a textbook value for a long time (Ward, 1973). Separation of radiolabelled $B$. subtilis glycan strands by size exclusion chromatography revealed that glycan strands display a wide mass distribution with the largest strands having a mass of $>250 \mathrm{kDA}$, corresponding to at least 500 DS units (Hayhurst et al., 2008). Further inspection of the glycan strands by AFM revealed strand lengths of up to 5000 $\mathrm{nm}$, corresponding to 5000 DS units. Again, a wide length distribution was found with an average length of $1300 \mathrm{~nm}$ (1300 DS units). Interestingly, when S. aureus glycan strands were analysed using similar methods, no such long strands were reported, suggesting that $S$. aureus $P G$ strands are short as reported earlier (Boneca et al., 2000) So, it appears that B. subtilis contains glycan strands of extreme lengths, which may be the result of polymerization of shorter glycan strands into one long chain rather than of continuous synthesis of one such strand. Glycan strand length is controlled by various systems that were recently identified in $S$. aureus and $E$. coli. $S$. aureus uses extracellular $N$ acetylglucosaminidases, notably, SagA, to control glycan strand length and cell wall stifness (Wheeler et al., 2015). In E. coli, a membrane bound endolytic transglycosylase MltG functions as a terminator of glycan strand elongation (Yunck et al., 2016). These results warrant a re-evaluation of the length of glycan strands, and their control, in several other organisms as it has fundamental implications for PG architecture.

Between different bacterial species, there is considerable variation in the composition of stem peptides that are linked to the carboxyl group of MurNAc (the landmark overview is Schleifer and Kandler, 1972). The stem peptides are synthesized as penta-peptide chains, containing L- and D-amino acids, and one dibasic amino acid, usually meso-diamoinopimelic acid $\left(m-\mathrm{A}_{2} \mathrm{pm}\right)$. In $B$. subtilis, the stem peptide composition is L-Ala(1)-D-Glu(2)-m-A2pm(3)-D-Ala(4)-D-Ala(5), with LAla $_{(1)}$ attached to the MurNac (Foster and Popham, 2002; Warth and Strominger, 1971) (Figure 2A). The peptide cross-bridge is formed by the action of a transpeptidase (see below) that links $\mathrm{D}-\mathrm{Ala}_{(4)}$ from one stem peptide to the free amino group of $m-\mathrm{A}_{2} \mathrm{pm}_{(3)}$ from another stem peptide. 

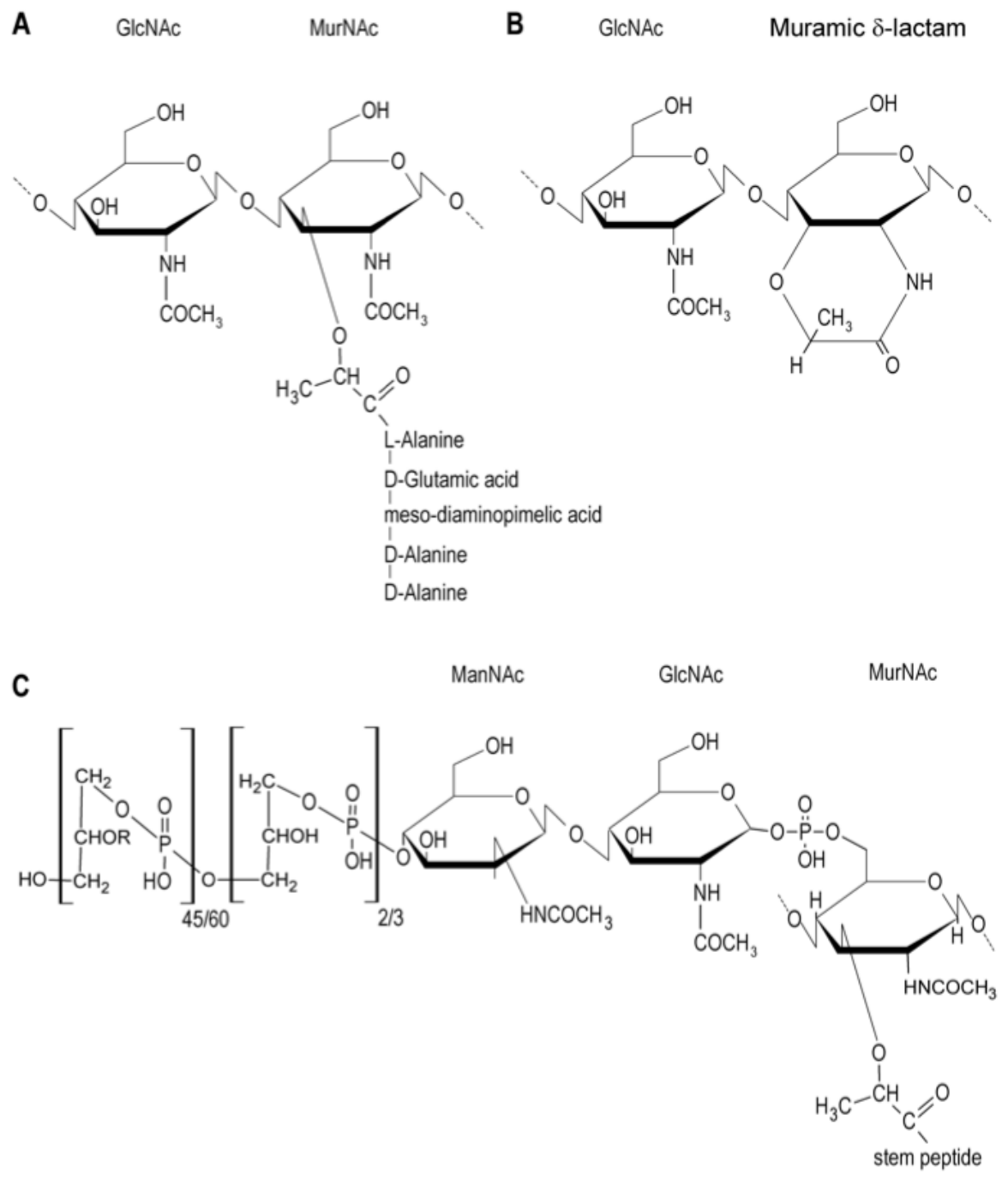

Figure 2. Structures of $B$. subtilis cell wall components: $A, B$ : The disaccharide subunits in peptidoglycan of the vegetative wall (A) and of the spore cortex with a muramic- $\delta$-lactam (B); C: the major wall teichoic acid, with its linkage to peptidoglycan via the MurNAc residue on the right hand side. $\mathrm{R}$ is either a D-alanine or glucose coupled to the $\mathrm{C} 2$ residues of poly(Gro-P).

After the incorporation of disaccharide subunits with stem peptides in glycan strands, the stem peptide can be modified in several ways to yield mature PG. Depending on the strain and growth conditions, the cross-linking index of PG is between 29 to $33 \%$ of muramic acid residues (Atrih et al., 1999). The terminal DAla residue on the peptide which had its D-Ala(4) cross-linked is removed during the transpeptidation reaction (see below), whereas the two terminal D-Ala 
residues on the other stem peptide are removed by the action of carboxypeptidase, either before or after the cross-linking reaction has taken place (see below).

Interestingly, the use of FDAAS showed that Bacillus division site is enriched in peptapeptide where the last D-Ala is not processed inmediately (Morales Angeles et al., 2017). Stem peptides that have not been cross-linked are usually present as tri-peptides which are amidated on the free carboxylic group of the $m-\mathrm{A}_{2} \mathrm{pm}$ (Atrih et al., 1999). Depending on growth media, the stem peptides occasionally (max 2.7\%) have a Glycine at position 5 (Atrih et al., 1999). De-N-acetylation of the glucosamine has been found to occur in $\sim 17 \%$ of the muropeptides, which results in incomplete digestion of the cell wall by lysozyme and may play a role in the regulation of autolysis of the cell wall (Atrih et al., 1999). Some evidence that acetylation of PG is important for its regulation has been reported for Bacillus anthracis. Mutant cells carrying deletions of two peptidoglycan deacetylases, BA1961 and BA3979, grow as long twisted chains, with thickened PG at some spots at the division site and lateral wall (Balomenou et al., 2013). More recently, PatB1, a secondary cell wall polysaccharide O-acetyltranferase in $B$. cereus, has been characterized (Sychantha et al., 2018).

\section{Spore peptidoglycan}

Upon nutrient starvation $B$. subtilis can switch from vegetative growth to the development of spores. The peptidoglycan of $B$. subtilis endospores is of a different composition than that of the vegetative cell. Spore PG consists of two layers, a thin inner layer that is closely apposed to the inner prespore membrane, and a thick outer layer, the cortex, that is close to the outer prespore membrane (for an extensive review, see Popham and Bernhards, 2016).

The inner layer is known as the primordial cell wall, or germ cell wall. The PG composition of the primordial wall is the same as that of the vegetative wall, and the primordial wall is not degraded during germination but forms the initial cell wall of the germinating spore. The cortex on the other hand is much thicker, contains a unique structure and is degraded during spore germination (Atrih et al., 1999; Atrih et al., 1996; Popham and Setlow, 1996; Warth and Strominger, 1969, 1972). The stem peptides are removed from around $50 \%$ of the muramic acid residues and subsequently the MurNAc residues are converted to muramic- $\delta$-lactam (see below, Figure 2B). This results in a dramatically lower amount of possible crosslinks. Additionally, around $24 \%$ of muramic acid residues have their stem peptides cleaved to single L-Ala residues precluding crosslinking. Thus, the crosslinking index for cortex PG is only $3 \%$. The $\delta$-lactam in the cortex PG is part of the substrate recognition profile for lytic enzymes that are specific to germination, but does not play a role in dormancy and spore dehydration (Popham et al., 1996).

\section{Peptidoglycan architecture}

Our understanding of the architecture of the cell wall is still far from perfect, but in the past few years significant advances using advanced microscopical techniques have been made (see Vollmer and Seligman, 2010). The classical model for PG 
architecture, states that the glycan strands run parallel to the plasma membrane and was first put forward by Weidel and Pelzer (Weidel and Pelzer, 1964). With the glycan strands parallel to the membrane and the stem peptides forming crossbridges, PG is organised in several layers with the number of layers in the cell wall being different between Gram-negative and Gram-positive bacteria (Höltje, 1998; Vollmer and Höltje, 2004).

Meroueh et al. elucidated the 3D solution structure of a synthetic GlcNAcMurNAc(-pentapeptide)-GIcNac-MurNAc(-pentapeptide) with NMR, providing the first glimpse of organization within a PG strand (Meroueh et al., 2006). The glycan backbone forms a right-handed helix with a periodicity of three disaccharide subunits, resulting in a threefold symmetry and a maximum of three neighbouring glycan strands that can be engaged in crosslinks. It is not known whether these features can be extrapolated to model long glycan strands that are cross-linked, especially since PG is normally stretched by turgor pressure, which puts constraints on the spatial organization of PG.

Cryo-TEM revealed that the $B$. subtilis cell wall consists of an inner wall zone (IWZ, Figure 1A), the Gram-positive equivalent of the periplasm, and an outer wall zone (OWZ), containing the bacterial cell wall, with a thickness of about $33 \mathrm{~nm}$ (Matias and Beveridge, 2005) B. subtilis glycan strands are extremely long (on average $1300 \mathrm{~nm}$ ). Solid state NMR experiments on fully hydrated cell walls showed that the glycan strands are more rigid then the stem peptides, but that cross-linking of stem-peptides increases overall rigidity - thus the $S$. aureus cell wall with short glycan strands but an extremely high degree of cross-linking is more rigid than that of $B$.subtilis which has long glycan strands but not such a high degree of cross-linking (Kern et al., 2010).

AFM studies of gently broken cell walls revealed that the $B$. subtilis cell wall has a rough surface on the outside, but on the inside, where new $P G$ is added to the wall, cables of about $50 \mathrm{~nm}$ in width were identified that run almost parallel to the short axis of the cell (Hayhurst et al., 2008). Apparently helical cross-striations were observed along the cables with a periodicity of $\sim 25 \mathrm{~nm}$ and the authors presented a model where glycan strands are bundled into a $\sim 25 \mathrm{~nm}$ wide sheet that is coiled into a $\sim 50 \mathrm{~nm}$ wide helix (Figure 1B). Interestingly, the glycan strand length was notably reduced, and the regular cabling feature on the inside of the CW lost, when CW material was isolated from a MreC mutant (Hayhurst et al., 2008) . A parallel organization for glycan strands was also found in E. coli, C. crescentus (Gan et al., 2008), and Lactococcus lactis (Andre et al., 2010). In S. aureus, nascent $P G$ is laid down in concentric rings at the septum, again arguing for a parallel organization of glycan strands (Turner et al., 2010). Additional support for a parallel PG organization in Bacillus was provided by a combination of electron cryo-tomography and molecular dynamics simulations (Figure 1C) (Beeby et al., 2013). Beeby et al. found that peptidoglycan strands are arranged as circumferential furrows and not as coiled cables. Moreover, peptide crosslinks are placed parallel to the long axis of the cell as denatured sacculi in which peptide crosslinks are broken increase in length but not in width (Beeby et al., 2013). Cryotomography also points to circumferential organization of PG strands 
and provides no indication that coils exist (Tocheva et al., 2013). The architecture of side wall PG was found to change from an irregular architecture in exponential growth phase to an ordered cable-like architecture in stationary phase, and PG thickness increased slightly in stationary phase (Li et al., 2018). AFM experiments on hydrated PG show a gel-like structure with large and deep pores on the outside surface and much denser material on the inside (Pasquina-Lemonche et al., 2020).

\section{Anionic polymers}

Wall teichoic acids (WTA) and lipoteichoic acid (LTA) constitute up to $60 \%$ of the dry weight of the cell wall in $B$. subtilis and provide an overall negative charge to the cell wall (for an extensive review see Neuhaus and Baddiley, 2003). Both WTA and LTA are important as cells that cannot produce either LTA or WTA show morphological aberrations and can only be grown under certain conditions, whereas the absence of both is lethal (Swoboda et al., 2010). LTA and WTA have several functions: (i) they can act as a reservoir for mono- and divalent cations, and cation binding in turn regulates porosity of the cell wall; (ii) their presence regulates the activity of autolysins; (iii) they can act as a scaffold for the anchoring of cell-surface proteins; (iv) WTAs function as the receptors for phage binding; (v) WTAs mediate DNA binding during competence and (vi) their distribution is important for the regulation of cell division (Brown et al., 2013; Mirouze et al., 2018; Rahman et al., 2009; Swoboda et al., 2010). When grown under phosphate limiting conditions, teichuronic instead of teichoic acids are used, as teichuronic acid is free of phosphate. However, not all teichoic acid is replaced by teichuronic acid (Bhavsar et al., 2004).WTA is covalently attached to the C6 of a MurNAc residue in the cell wall via its 'linkage unit': 1,3-glycerol-phosphate (Gro-P) ${ }_{[2}$ or 3]-Nacetyl-mannose (ManNAc)- $\beta 1,4-G l c N a c-p h o s p h a t e$. Coupled to the linkage unit is a chain of poly(Gro-P) that can have either D-ala or glucose coupled to the C2, with chain lengths varying from 45 to 60 residues (Neuhaus and Baddiley, 2003). The composition of the chain varies between Bacillus species. A minor form of WTA comprises a polymer chain of N-acetylgalactosamine (GalNAc) and glucosephosphate instead of poly-(Gro-P). Teichuronic acid consists of a chain of repeating glucuronic acid-N-GalNAc disaccharide residues (19-21 as determined for B. subtilis W23, Wright and Heckels, 1975), coupled to the cell wall via a phospho-di-ester bond similar to teichoic acid. LTA consists of a chain of poly(Gro-P) which contains D-Ala, glucose, or N-acetylglucosamine coupled to $\mathrm{C} 2$ in 40 to $60 \%$ of the units. LTA is anchored to the cytoplasmic membrane via a lipid anchor composed of a gentibiosyl-diacylglycerol, which is linked to the poly(Gro$P)$ via a glucose disaccharide. Nothing is known about the architecture of the anionic polymers in Gram-positives: they could be arranged either parallel or perpendicular to the cytoplasmic membrane, although the perpendicular orientation is favoured in discussions and figures on the topic. It has been established though that WTA and teichuronic acid are incorporated close to the membrane and move through the wall following the "inside-to-outside" growth mechanism also proposed for PG (see Brown et al., 2013; Neuhaus and Baddiley, 2003). 


\section{Cell wall synthesis}

All cell wall components are synthesized as precursors in the cytoplasm, which then need to be flipped across the cytoplasmic membrane to be incorporated into the cell wall. Interestingly, precursors for PG, WTA and teichuronic acid all use undecaprenyl-phosphate as carrier lipid. Synthesis of the cell wall can be subdivided in three stages: 1) synthesis of the cytoplasmic precursor and linkage to the carrier lipid; 2) flipping across the membrane; 3) incorporation of the precursor into the cell wall. These stages will be discussed individually for the different wall components. PG and anionic polymer biosynthesis has been described in several reviews and book chapters (Neuhaus and Baddiley, 2003; Rogers et al., 1980; van Heijenoort, 2001; Vollmer and Bertsche, 2008), and specifically for $B$. subtilis by Foster and Popham (Foster and Popham, 2002) and Bhavsar and Brown (Bhavsar and Brown, 2006). Therefore, in this chapter the chemical reactions involved in PG synthesis will only be discussed briefly.

\section{PG synthesis stage 1 - synthesis of Lipid II}

The first dedicated step in PG precursor synthesis is the conversion of UDPGlcNac to UDP-MurNac. A schematic outline of the steps in PG precursor synthesis and the proteins involved is shown in Figure 3. Many of the proteins have been assigned based on sequence similarity to $E$. coli proteins, for which the function has been demonstrated (see Foster and Popham, 2002). The genes for murE, mraY, murD, murG, and murB are all present in one operon, whereas murA (or murAA), murZ (or murAB) and murC lie on different places on the chromosome. MurA and MurZ are highly similar, can catalyse the same reaction and are possibly redundant, as a second murA copy is only present in low $G+C$ Gram-positive bacteria. MurB is essential and the genetic organisation of murB in the $d c w$ gene-cluster is necessary for efficient growth and sporulation (Real and Henriques, 2006). MurC, D, E and F are all ATP-dependent amino acid ligases and have conserved ATP and amino acid binding motifs and common kinetic mechanisms (see El Zoeiby et al., 2003). D-Ala is generated from L-Ala by the action of an alanine racemase (Diven et al., 1964), encoded by the dal (or alr) gene (Ferrari et al., 1985). D-Ala can function as a precursor for D-Glu, which can be generated by the action of a D-Alanine aminotransferase (dat or yheM) (Noback et al., 1998), but D-Glu can also be generated by a Glu racemase of which $B$. subtilis has two, RacE and YrpC (Ashiuchi et al., 1999; Fotheringham et al., 1998). The cytoplasmic part of the precursor synthesis pathway is reviewed in (Barreteau et al., 2008; Manat et al., 2014).

Subsequently, at the cytoplasmic membrane, the monosaccharide-pentapeptide is coupled to a lipid and the second sugar is added (see Bouhss et al., 2008). MraY catalyzes the transfer of the phospho-MurNAc-pentapeptide moiety to the membrane acceptor undecaprenyl phosphate (bactoprenol), giving MurNAc(pentapeptide)-pyrophosphoryl-undecaprenol (or lipid I). Then, UDP-GIcNAc is linked via a $\beta$-(1,4)-linkage to lipid I, yielding GlcNAc- $\beta-(1,4)-M u r N A c-$ (pentapeptide)-pyrophosphoryl-undecaprenol (or lipid II). The coupling of the disaccharide precursor to a lipid molecule is required to facilitate the translocation of a hydrophilic substrate from one aqueous environment to another through the hydrophobic membrane. MraY and MurG have been found to interact with each 
other and cytoskeletal proteins MreB, MreD and FtsZ that are involved in positioning the PG synthesis machinery in E. coli and C. crescentus (Aaron et al., 2007; Mohammadi et al., 2007; White et al., 2010).

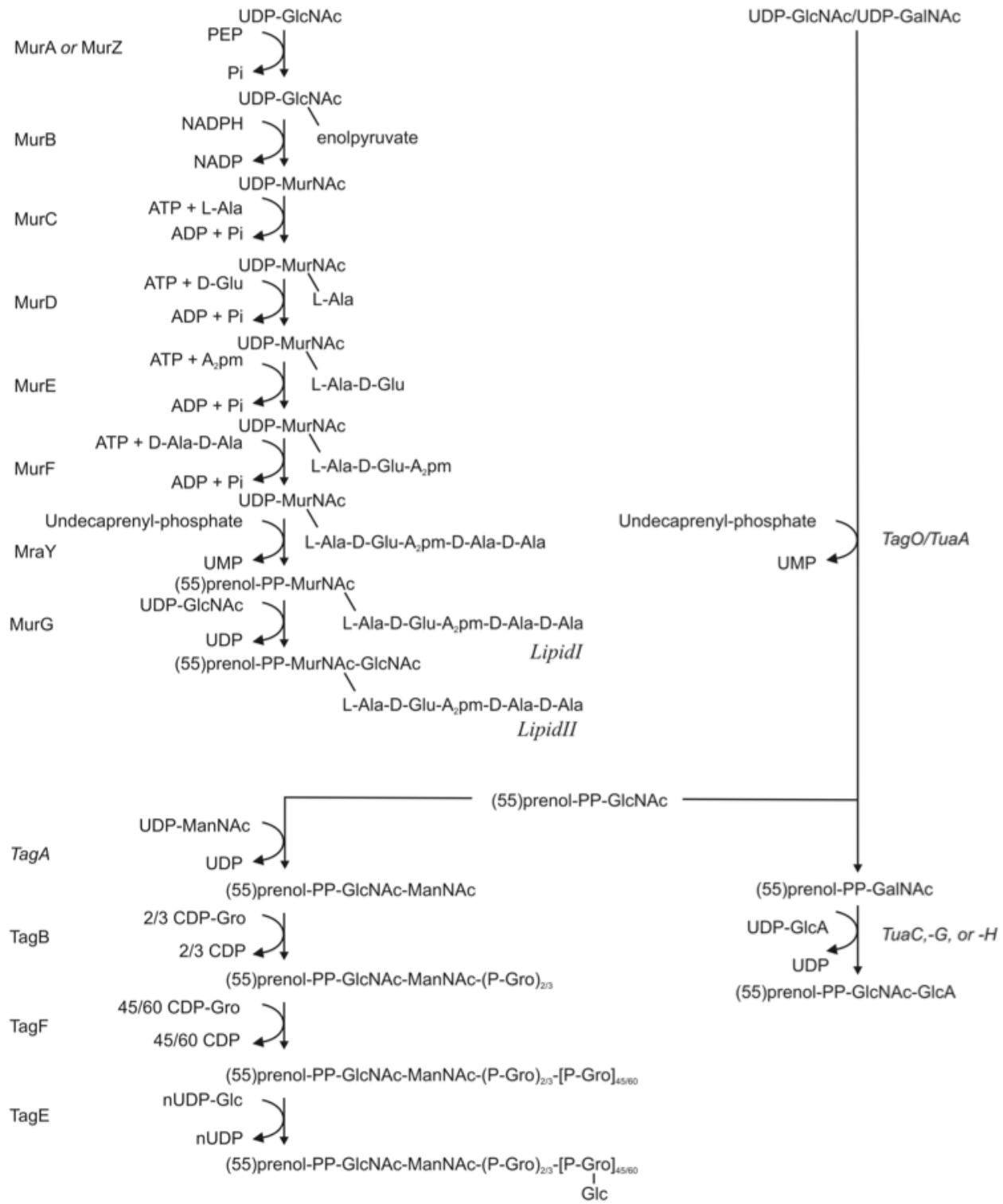

Figure 3. Synthesis of precursors of peptidoglycan, teichoic acid and teichuronic acid. Proteins denoted in italics have been predicted to be involved in the synthesis steps indicated. (55)prenol is undecaprenol. For more information see the text. 
Teichoic/teichuronic acid synthesis stage 1

As with PG synthesis, the synthesis of the precursors of anionic polymers starts with UDP-linked $\mathrm{N}$-acetylated sugars, glucosamine for teichoic acid and galactosamine for teichuronic acid (Figure 3 ). In $B$. subtilis 168, the genes involved in WTA synthesis are tagABDEFGHO and gtaBmnaA (reviewed in Neuhaus and Baddiley, 2003). In the case of teichoic acid synthesis, the lipidlinkage reaction precedes the synthesis of the linkage unit and the elongation of the poly-(Gro-P) chain. This reaction is catalysed by TagO. Work from Eric Brown's group has shown that, unlike previously thought, WTA synthesis is not essential. However, the synthesis pathway can only be disrupted when tagO is deleted, either because otherwise undecaprenol that is also required for PG syntheis is sequestered, or because the accumulation of toxic WTA synthesis intermediates kills the cell (D'Elia et al., 2006a; D'Elia et al., 2006b). UDPManNAc, the product of an epimerization reaction of UDP-GIcNac catalysed by MnaA, is linked to undecaprenol-PP-GlcNac by TagA (Ginsberg et al., 2006; Zhang et al., 2006). TagD functions as a CTP-glycerol-3-phosphate cytidyltransferase to provide CDP-Gro and GtaB functions as a UTP-glucose-6phosphate uridyltransferase to provide UDP-glucose. TagB functions as the 'Tag primase' that adds the first glycerol-phosphate residues to undecaprenol-PPGlcNAc-ManNAc, the disaccharide linkage unit (Ginsberg et al., 2006). Elongation of the glycerol-phosphate chain is mediated by TagF (Pereira et al., 2008) and glucosylation by TagE, the only non-essential gene product in the tag operons (Pooley et al., 1991). Coupling of D-Ala to the C2 on poly-(Gro-P) is mediated by the genes in the dltABCDE operon. The lipid-linked precursor is then ready to be translocated across the cytoplasmic membrane. The genetics of LTA biosynthesis are still enigmatic. The ditABCDE operon plays a role in D-alanylation of LTA and the $y p f P$ gene functions to couple the gentiobiosyl to the lipid anchor.

Teichuronic acid synthesis is mediated by the products of the tuaABCDEFGH operon. This operon is transcribed upon phosphate limitation (Soldo et al., 1999). The reactions involved have been characterized for $B$. subtilis strain W23, and interestingly, synthesis of one repeating unit coupled to a lipid anchor takes place in the cytoplasm, after which the precursor is flipped and the repeating unit is added to a growing chain on a lipid anchor in the periplasm, before coupling of the chain to PG. WTA in $B$. subtilis W23 contains poly(ribitol-5-P) instead of poly(glycerol-3-P) and its is synthesized by a set of $\operatorname{tar}$ genes. $\operatorname{Tar} O,-A,-B$, and $-F$ are homologous to their tag equivalents, although TarF acts only as a primase to add one glycerol-3-P to the linkage unit, after which TarK primes this product by adding one ribitol-5-P and TarL acts as the poly(ribitol-5-P) polymerase (see Swoboda et al.). In LTA synthesis, the poly(glycerol-3-P) chain is synthesized on the outside of the cell - but the glycolipid anchor diglucosyl-diacylglycerol is synthesized at the cytoplasmic side of the membane through coupling of UDP-Glc and diacylglycerol by UgtP (Jorasch et al., 1998).

\section{Peptidoglycan synthesis stage 2 - translocation of Lipid II}

Over the past decade, several candidate proteins have been proposed to function as specific translocase or flippase for Lipid II, and various translocases have been identified over the last decade (reviewed in Ruiz, 2016; Scheffers and Tol, 2015). 
Experimental evidence for translocation activity has now been provided for three different protein families: the FtsW/RodA family (Mohammadi et al., 2014; Mohammadi et al., 2011), MurJ (Ruiz, 2008; Sham et al., 2014) and Amj (Meeske et al., 2015).

FtsW and RodA homologues were originally proposed as candidate translocases. RodA and FtsW are members of the SEDS (Shape, Elongation, Division and Sporulation) family and homologues have been found in many bacteria that contain a cell wall, but not in the wall-less Mycoplasma genitalium or the archaeon Methanococcus janasschii (Henriques et al., 1998). RodA and FtsW are integral membrane proteins (generally predicted to have ten membrane spanning a-helices), which is in accordance with the suggestion that they may channel the lipid precursors to their cognate PBPs (Ehlert and Holtje, 1996; Ishino and Matsuhashi, 1981; Ishino et al., 1986). Reconstituted FtsW is capable of flipping a fluorescently labelled Lipidll analogue, NBD (7-nitro-2,1,3-benzoxadiazol-4-yl)LipidIl (van Dam et al., 2007) in an energy independent manner (Mohammadi et al., 2011). The flippase activity required the FtsW transmembrane domain 4 (TM4) and the charged amino acids in TM4, Arg145 and Lys153, may be responsible for the interaction with Lipid II as mutation of these residues abolished FstW activity (Mohammadi et al., 2014). However, the recent discovery that FtsW and RodA act as glycosyl transferases in combination with a Class B PBP strongly suggests that their most important function is elongation of glycan strands (Cho et al., 2016; Emami et al., 2017; Meeske et al., 2016; Sjodt et al., 2020; Taguchi et al., 2019), although the possibility that FtsW/RodA simultaneously flip Lipidll and then use it to elongate a glycan strand cannot formally be excluded.

The MurJ Lipidll flippase is a 14 TM member of the MOP (multidrug/oligosaccaridyllipid/polysaccharide) exporter super family (Hvorup et al., 2003). Other MOP exporters transport other undecaprenol-linked precursors such as the O-antigen flippase Wzx in Pseudomans aeruginosa (Burrows and Lam, 1999). MurJ was identified in a bioinformatics search for genes that are specific for bacteria that have a cell wall, is essential in E. coli, and when depleted leads to cell shape defects (Inoue et al., 2008; Ruiz, 2008). The Ruiz, Kahne and Bernhardt laboratories developed an assay to test the Lipidll flipping ability of $E$. coli MurJ in vivo based on the activity of the toxin colicin M (ColM) (Sham et al., 2014). ColM cleaves periplasmic Lipid II producing PP-disaccharide-pentapeptide, which is further cleaved by carboxypeptidase to tetrapeptide, whereas Lipid II that has remained in the inner membrane leaflet will not be cleaved as ColM cannot cross the inner membrane. Thus, ColM mediated production of PP-disaccharide-tetrapeptide is a measure for Lipidll flippase activity, whereas Lipidll accumulation in the membrane is a measure for blocked flippase. Use of a single-Cys MurJ mutant (MurJA29C) that can be inactivated by the addition of MTSES (2-sulfonatoethyl methanethiosulfonate) allowed the monitoring of Lipidll translocation in the presence and absence of active MurJ. Modification of MurJA29C also abolished PG synthesis in vivo, whereas unmodified MurJA29C allowed growth (Sham et al., 2014). Recent studies have shown that the flippase activity of MurJ is dependent on membrane potential (Rubino et al., 2018). The crystal structure of MurJ, from Thermosipho africanus and E. coli (Kuk et al., 2017; Zheng et al., 2018) showed 
that the protein contains a central cavity with a Lipidll binding site, surrounded by an $\mathrm{N}$-terminal lobe (TMS 1-6) and a C-terminal domain (TMS 7-14). A further structural study revealed both inward and outward conformations of MurJ and strongly suggests that MurJ functions via an alternating access mechanism which is likely driven by $\mathrm{Na}^{+}$import (Kuk et al., 2019). This model is in line with further biochemical and mutational studies (Kumar et al., 2019; Zheng et al., 2018). Key in the mechanism is a triad of residues, Arg24, Asp 25 and Arg255 on TMs 1 and 8, of which the unusual positive charge is shielded by the binding of the pyrophosphate moiety on Lipidll (Kuk et al., 2019). Purified MurJ contains bound Cardiolipin (CL) and competition studies show that CL can compete with Lipidll for binding to MurJ, suggesting a possible control mechanism for MurJ by membrane components (Bolla et al., 2018).

Surprisingly, B. subtilis homologues of MurJ are not essential for growth (Fay and Dworkin, 2009), even more, a deletion of all 10 B. subtilis MOP homologues does not have important effects of growth and morphology (Meeske et al., 2015). This observation led to the suggestion that an additional flippase may be present. A synthetic lethal screen in a strain in which four the MOP members most homologous to E. coli MurJ (YtgP, YabM, SpoVD and YkvU) were deleted, identified Amj (Alternate to MurJ) as a putative flippase. The role of Amj as a flippase was confirmed in E. coli - Amj could compensate for the loss of MurJ and was functional in the in vivo ColM flippase assay (Meeske et al., 2015). Interestingly, it was impossible to make a double deletion of amj and $y t g P$, the closest homologue to E. coli MurJ, indicating that YtgP is the B. subtilis MurJ homologue (Meeske et al., 2015).

It is now established that MurJ is a true Lipidll flippase, and the past five years have shown tremendous progress in the discovery of the flippase mechanism. Outstanding questions are whether or not SEDS proteins such as FtsW and RodA may flip the Lipidll that they attach to growing glycan strands, and what the mechanism is of Amj.

\section{Anionic polymer synthesis stage 2 - translocation}

Translocation of teichoic acid precurors is probably mediated by TagGH. Both $\operatorname{tag} G$ and $\operatorname{tag} H$ are essential genes encoding a two-component $A B C$ transporter. Limited expression of these genes results in cells with aberrant cell walls containing reduced amounts of both the major and minor components of WTA (Lazarevic and Karamata, 1995). Translocation of the repeating unit of teichuronic acid is thought to be mediated by TuaB, a protein with 11 or 12 predicted transmembrane helices that is homologous to the Wzx proteins described above (Soldo et al., 1999). The glycolipid anchor for LTA synthesis is flipped to the outside of the cell by LtaA (Grundling and Schneewind, 2007a).

Peptidoglycan synthesis stage 3 - incorporation of precursors into peptidoglycan The third and final stage of PG biosynthesis takes place at the outer side of the cytoplasmic membrane and involves the polymerization of the translocated disaccharide-peptide units and their incorporation into the growing PG. The periplasmic space poses a topological problem in PG synthesis: the lipid-linked 
precursor and the majority of the proteins catalyzing PG synthesis are embedded in the membrane, whereas the PG to which the precursor has to be attached is at a distance of some $22 \mathrm{~nm}$. There is quite some flexibility between the TGase and TPase domains in Class A PBPs that could account for this bridging, especially if one imagines that a new glycan strand is being assembled the membrane, and the threaded into the cell wall at a slight distance from the membrane. Dmitriev and coworkers have proposed that the membrane bulges to bring the cell wall and the sites of PG synthesis (Dmitriev et al., 2005). It still has to be resolved whether such membrane bulging occurs.

Incorporation of PG-precursors into PG is mediated mainly through the action of the so-called penicillin-binding proteins (PBPs) and the SEDS proteins RodA and FtsW. PBPs catalyze the transglycosylation and transpeptidation reactions responsible for the formation of the glycosidic and peptide bonds of the PG. In the transglycosylation reaction, the glycan chain is elongated by the formation of a glycosidic bond between Lipid II and the lipid-linked PG strand. An elegant in vitro study from Nguyen-Distèche and co-workers, using E. coli PBP1b, showed that in this reaction the reducing end of MurNac on the growing glycan chain acts as a donor and the C-4 carbon of GlcNac moiety of Lipid II acts as an acceptor (Fraipont et al., 2006), as was previously concluded for cell wall growth in $B$. licheniformis (Ward and Perkins, 1973). As a result, undecaprenyl-phosphate will be released from the donor (and flipped across the membrane to act again as a substrate for MraY), and the growing glycan chain will remain attached to the membrane through the lipid anchor at its new reducing end. Termination of elongation of peptidoglycan strands is performed by LTs (lytic transglycosylases). In E. coli, MltG has been identified recently as a terminase (Yunck et al., 2016). MltG is the first LT reported to localize at the inner membrane and interacts with PBP1b. In the absence of MltG, the amount of anhydromuropeptides, which are a characteristic feature of the caps of glycan strands, was reduced, a direct measure of glycan strand length confirmed that the overll length of glycan strands was increased (Yunck et al., 2016).

PG transglycosylation is not only performed by PBPS, but also by SEDS proteins as has been recently demonstrated. Cells lacking the four known aPBPs responsible for $P G$ polymerization are still viable - which means there must be at least one additional enzyme that could perform transglycosylation. RodA, a member of the SEDS proteins, has been identified as the novel glycosyltranferase (Emami et al., 2017; Meeske et al., 2016). Transglycosylation activity was also shown for FtsW, and interestingly the activity was dependent on the presence of the cognate Class B TPase (Taguchi et al., 2019). A recent co-crystal structure from the homologous RodA-PBP2 elongasome complex from Thermus thermophilus revealed the activation of RodA glycosyl transferase activity by the extracytoplasmic 'pedestal' domain of PBP2, and large movements of the PBP2 cytoplasmic domain that allow this activation as well as transpeptidase activity (Sjodt et al., 2020). Combined, these papers provide a solid basis for understanding the activity of SEDS/Class B PBP protein pairs as key parts of the elongasome and divisome machineries that lay down tracks of peptidoglycan, which will be further modified, and/or used as a template, for subsequent 
synthesis reactions (Cho et al., 2016). The role of Class A PBPs, which do mediate some $80 \%$ of total PG synthesis, is probably to further synthesize PG on these tracks (Cho et al., 2016), as well as modifying the PG to mature PG that is less sensitive to the activity of specific hydrolysases (Straume et al., 2020).

In the transpeptidation reaction, the terminal D-Ala-D-Ala of one stem peptide is bound to the active site of the enzyme through binding of the penultimate D-Ala to the catalytic Serine in the protein, concomitant with the release of the terminal DAla. Subsequently, the stem-peptide is coupled to the dibasic $A_{2} p m$ that functions as an acceptor on another stem-peptide. The acceptor peptide does not have to be a penta-peptide: for example, tri- and tetra-peptide acceptors can also be used by E. coli PBP1b (Bertsche et al., 2005). However, the specificity for acceptor substrates may be more stringent for other transpeptidases (see below). Terminal D-Ala residues are removed from acceptor stem peptides by the D,Dcarboxypeptidase activity of some PBPs. This reaction can also take place before the stem-peptide has been cross-linked to another peptide, thus presenting a level of control for acceptor substrate specificity. Finally, PBPs with D,Dendopeptidase activity can cleave cross-links in order to allow the PG mesh-work to expand.

During spore PG synthesis, B. subtilis expresses a third, specialized SEDS/Class B PBP pair consisting of SpoVD (B PBP) and SpoVE (SEDS), which are essential for sporulation(Bukowska-Faniband and Hederstedt, 2013; Daniel et al., 1994b; Henriques et al., 1992; Khanna et al., 2020). Spore PG is different from vegetative PG, as around $50 \%$ of the muramic acid residues are converted to muramic- $\delta$ lactam by the concerted efforts of the CwID and PdaA proteins. CwID acts as an amidase and removes the stem peptide from muramic acid, after which PdaA acts as a de-acetylase and generates the lactam ring (Gilmore et al., 2004). This process must be tightly regulated as every second muramic acid in the PG strand is converted to muramic- $\delta$-lactam and the reactions have to occur before the stem peptide in involved in a transpeptidation reaction. Nothing is known about regulatory factors for CwID or for PdaA. PdaA is expressed in the prespore only (Fukushima et al., 2002) whereas CwID is expressed both in the prespore and in the mother cell, and mother cell expression alone is enough to produce spores with normal muramic- $\delta$-lactam levels (Gilmore et al., 2004; Sekiguchi et al., 1995). Interestingly, both proteins have to cross the membrane from different compartments and act in the intermembrane space between the inner- and outer prespore membrane where they generate a highly ordered muramic- $\delta$-lactam distribution.

\section{Anionic polymer synthesis stage 3}

It is not known how teichoic and teichuronic acid are coupled to PG. Chain formation during teichuronic acid biosynthesis occurs in the periplasm and is thought to be mediated by TuaE, which is a membrane protein homologous to a polymerase involved in O-antigen synthesis (Soldo et al., 1999).

B. subtilis contains four paralogues of LtaS, the enzyme that can synthesize the poly(glycerol-3-P) backbone on the glycolipid anchor. Of these homologues only 
LtaS $_{\mathrm{BS}}$ is capable of replacing the single LtaS of $S$. aureus (Grundling and Schneewind, 2007b). Reconstitution of LTA synthesis activity in vitro has shown that of the four LtaS paralogues, YvgJ acts as a primase adding the first glycerolphosphate onto the glycolipid anchor, with LtaS $_{B S}$ acting as the housekeeping LTA synthase and YqgS as a sporulation specific LTA synthase and Yfnl as the LTA synthase active during stress. Yfnl can also act as a primase and its expression is controlled by $\sigma \mathrm{M}$ and phosphorylation by PrkC, hence its suggested role as a LTA synthase active during stress (Pompeo et al., 2018; Schirner et al., 2009; Wörmann et al. 2011).

\section{Penicillin Binding Proteins in B. subtilis: activity and expression}

Penicillin binding proteins (PBPs) belong to the family of acyl serine transferases, which comprises high molecular weight (HMW; > $60 \mathrm{kDa}$ ) PBPs (catalysing transglycosylation and transpeptidation reactions), low molecular weight (LMW; < $60 \mathrm{kDa}$ ) PBPs (catalysing carboxypeptidase and endopeptidase reactions) and $\beta$ lactamases (which cleave $\beta$-lactam rings and thereby mediate resistance to penicillin and analogous antibiotics) (Ghuysen, 1991). An overview of $B$. subtilis PBPs is given in Table 1. The functional redundancy between PBPs from all classes has made it difficult to assign specific functions to individual PBPs in $B$. subtilis and most of our current understanding of PBP functions in $B$. subtilis is the result of extensive genetic studies performed by Popham, Setlow and their coworkers.

HMW PBPs are further subdivided into two classes, $A$ and $B$, on the basis of their primary structure and the catalytic activity of the N-terminal domain (Goffin and Ghuysen, 1998). All HMW PBPs are anchored to the cytoplasmic membrane via a transmembrane helix.

Class A PBPs have an N-terminal domain with transglycosylase activity and a Cterminal domain with transpeptidase activity, which makes them capable of both glycan strand elongation and formation of cross-links between glycan strands. Therefore, these proteins are also known as bifunctional PBPs. B. subtilis contains four genes encoding Class A PBPs, but the ponA gene gives rise to both PBP1a and PBP1b which are different due to C-terminal processing of the protein (Popham and Setlow, 1995). PBP1 performs a non-essential function in cell division, as mutants exhibit slower growth and form slightly elongated cells (Popham and Setlow, 1995). Claessen et al. showed that PBP1 also plays a role in pole maturation and cell elongation, and shuttles between the division site and lateral wall (Claessen et al., 2008). PBPs $-2 c$ and $-2 d$ are involved in sporulation, as cells lacking both of these PBPs are incapable of forming viable spores (McPherson et al., 2001). Both PBPs are expressed in the prespore during sporulation, and in the double mutant, $P G$ is synthesized that has an altered composition and does not completely surround the prespore, suggesting that these PBPs play a role in the synthesis of the germ cell wall that serves as a template for synthesis of cortex PG (McPherson et al., 2001). PBP4 is probably involved in synthesis of the vegetative cell wall, but a pbp4 deletion has no obvious phenotype (Popham and Setlow, 1994). A screen of pbp mutants for the capacity to incorporate unnatural D-amino acids revealed that PBP4 accounts for 


\begin{tabular}{|c|c|c|c|c|}
\hline Class & Gene & Protein & Function/expression & Localisation (method) ${ }^{a}$ \\
\hline \multirow{4}{*}{ A } & $\begin{array}{l}\text { ponA (Popham } \\
\text { and Setlow, } \\
\text { 1995) }\end{array}$ & PBP1a/b & $\begin{array}{l}\text { TG/TPase } \text { involved in cell division and } \\
\text { diameter control in elongation (Claessen et } \\
\text { al., 2008; Dion et al., 2019), vegc (Popham } \\
\text { and Setlow, 1995) }\end{array}$ & $\begin{array}{l}\text { septal (IF, GFP) (Pedersen et al., } \\
\text { 1999; Scheffers et al., 2004), distinct } \\
\text { foci and bands at cell periphery } \\
\text { (Claessen et al., 2008) }\end{array}$ \\
\hline & $\begin{array}{l}\text { pbpD (Popham } \\
\text { and Setlow, } \\
\text { 1994) }\end{array}$ & PBP4 & $\begin{array}{l}\text { veg (Popham and Setlow, 1994) very active } \\
\text { TPase - responsible for incorporation of } \\
\pm 50 \% \text { of DAA-analogues (Fura et al., 2015) }\end{array}$ & $\begin{array}{l}\text { distributed along membrane with } \\
\text { distinct spots at periphery (GFP) } \\
\text { (Scheffers et al., 2004) }\end{array}$ \\
\hline & $\begin{array}{l}\text { pbpF (Popham } \\
\text { and Setlow, } \\
\text { 1993b) }\end{array}$ & PBP2C & $\begin{array}{l}\text { synthesis of spore PG (McPherson et al., } \\
\text { 2001), veg, late stages of spo (Popham } \\
\text { and Setlow, 1993b) }\end{array}$ & $\begin{array}{l}\text { distributed along membrane, } \\
\text { redistributed to prespore during } \\
\text { sporulation (GFP)(Scheffers et al., } \\
\text { 2004; Scheffers, 2005) }\end{array}$ \\
\hline & $\begin{array}{l}\text { pbpG (Pedersen } \\
\text { et al., 2000) }\end{array}$ & PBP2d & $\begin{array}{l}\text { synthesis of spore PG (McPherson et al., } \\
\text { 2001), spo (Pedersen et al., 2000) }\end{array}$ & $\begin{array}{l}\text { distributed along membrane } \\
(\text { GFP) })^{115} \text { (Scheffers et al., 2004), } \\
\text { redistributed to prespore during } \\
\text { sporulation }^{119} \text { (Scheffers, 2005) }\end{array}$ \\
\hline \multirow{6}{*}{ B } & $\begin{array}{l}\text { pbpA } A^{121} \text { (Murray } \\
\text { et al., 1997) }\end{array}$ & PBP2a & $\begin{array}{l}\text { synthesis of lateral wall (Wei et al., 2003), } \\
\text { veg (Murray et al., 1997) }\end{array}$ & $\begin{array}{l}\text { evenly distributed along the } \\
\text { membrane (GFP)(Scheffers et al., } \\
\text { 2004) } \\
\text { depends on Lipidll (Lages et al., } \\
\text { 2013) }\end{array}$ \\
\hline & $\begin{array}{l}\text { pbpH (Wei et al., } \\
2003)\end{array}$ & $\mathrm{PbpH}$ & $\begin{array}{l}\text { synthesis of lateral wall veg, (Wei et al., } \\
\text { 2003) }\end{array}$ & $\begin{array}{l}\text { evenly distributed along the } \\
\text { membrane (GFP)(Scheffers et al., } \\
\text { 2004) } \\
\text { depends on Lipidll (Lages et al., } \\
\text { 2013) }\end{array}$ \\
\hline & $\begin{array}{l}\text { pbpB (Yanouri et } \\
\text { al., 1993) }\end{array}$ & PBP2b & $\begin{array}{l}\text { cell division specific TPase (Daniel et al., } \\
\text { 2000), veg, spo (Yanouri et al., 1993) }\end{array}$ & $\begin{array}{l}\text { septal (IF, GFP) (Daniel et al., 2000; } \\
\text { Scheffers et al., 2004) }\end{array}$ \\
\hline & $\begin{array}{l}\text { pbpC (Murray et } \\
\text { al., 1996) }\end{array}$ & PBP3 & $\begin{array}{l}\text { not known, veg, low expression during spo } \\
\text { (Murray et al., 1996) }\end{array}$ & $\begin{array}{l}\text { distinct foci and bands at cell } \\
\text { periphery (GFP)(Scheffers et al., } \\
\text { 2004) }\end{array}$ \\
\hline & $\begin{array}{l}\text { spoVD (Daniel et } \\
\text { al., 1994a) }\end{array}$ & SpoVD & $\begin{array}{l}\text { synthesis of spore PG, spo (Daniel et al., } \\
\text { 1994a) }\end{array}$ & $\begin{array}{l}\text { outer prespore membrane (GFP) } \\
\text { (Fay et al., 2010) }\end{array}$ \\
\hline & $\begin{array}{l}\text { pbpl (Wei et al., } \\
2004)\end{array}$ & PBP4b & not known, spo (Wei et al., 2004) & $\begin{array}{l}\text { evenly distributed along the } \\
\text { membrane (GFP)(Scheffers et al., } \\
\text { 2004) }\end{array}$ \\
\hline \multirow{4}{*}{$\begin{array}{l}\text { Low MW } \\
\text { CPase }\end{array}$} & $\begin{array}{l}\text { dacA (Todd et } \\
\text { al., 1986) }\end{array}$ & PBP5 & $\begin{array}{l}\text { major D,D-carboxypeptidase (Lawrence } \\
\text { and Strominger, 1970) }\end{array}$ & $\begin{array}{l}\text { distributed along membrane with } \\
\text { distinct spots at periphery (GFP) } \\
\text { (Scheffers et al., 2004) }\end{array}$ \\
\hline & $\begin{array}{l}\text { dacB (Buchanan } \\
\text { and Ling, 1992) }\end{array}$ & PBP5* $^{*}$ & $\begin{array}{l}\text { control of peptide crosslinking in spore PG } \\
\text { (Popham et al., 1999), spo (Buchanan and } \\
\text { Ling, 1992) }\end{array}$ & not known \\
\hline & $\begin{array}{l}\text { dacC (Pedersen } \\
\text { et al., 1998) }\end{array}$ & PBP4a & $\begin{array}{l}\text { not known, late stationary phase (Pedersen } \\
\text { et al., 1998) }\end{array}$ & $\begin{array}{l}\text { distinct foci and bands at cell } \\
\text { periphery (GFP)(Scheffers et al., } \\
\text { 2004) }\end{array}$ \\
\hline & $\begin{array}{l}\text { dacF (Wu et al., } \\
\text { 1992) }\end{array}$ & DacF & $\begin{array}{l}\text { control of peptide crosslinking in spore PG } \\
\text { (Popham et al., 1999), spo (Wu et al., } \\
\text { 1992) }\end{array}$ & not known \\
\hline \multirow{2}{*}{$\begin{array}{l}\text { Low MW } \\
\text { EPase }\end{array}$} & $\begin{array}{l}\text { PbpE (Popham } \\
\text { and Setlow, } \\
\text { 1993a) }\end{array}$ & PBP4* & $\begin{array}{l}\text { not known, spo (Popham and Setlow, } \\
\text { 1993a) }\end{array}$ & $\begin{array}{l}\text { distinct foci and bands at cell } \\
\text { periphery (GFP)(Scheffers, 2005) }\end{array}$ \\
\hline & $P b p X$ & $\mathrm{PbpX}$ & not known, veg (Scheffers, 2005) & $\begin{array}{l}\text { septal, spiral outgrowth to both } \\
\text { asymmetric septa during sporulation } \\
\text { (Scheffers et al., 2004; Scheffers, } \\
\text { 2005) }\end{array}$ \\
\hline \multicolumn{5}{|c|}{$\begin{array}{l}\text { a IF: Immunofluorescence; GFP: fluorescence of a GFP-Fusion } \\
\text { b TGase: transglycosylase; TPase: transpeptidase; CPase: carboxypeptidase; EPase: endopeptidase } \\
\text { ' For the expression or transcription factor dependency of most pbp genes has been determined and is indicated; veg: } \\
\text { expression during vegetative growth; spo: expression during sporulation. Reprinted, with permission from ASM, from } \\
\text { (Scheffers and Pinho, 2005). }\end{array}$} \\
\hline
\end{tabular}


about $50 \%$ of the incorporation activity (Fura et al., 2015). This suggests that PBP4 plays an important role in transpeptidation, although given the absence of a phenotype, this role can be compensated in a PBP4 mutant. For a long time it was thought that Class A PBPs were the only proteins with transglycosylase activity, which led to the question why a mutant lacking all Class A PBPs is viable (McPherson and Popham, 2003) - which was recently resolved by the discovery that the SEDS-proteins are transglycosylases (Cho et al., 2016; Emami et al., 2017; Meeske et al., 2016). Nevertheless, it is evident that Class A PBPs play an important role in overall PG synthesis, being responsible for the major portion of PG in normal cells, crucial for width regulation, and modification of PG to a more mature form (Cho et al., 2016; Dion et al., 2019; Straume et al., 2020).

B. subtilis contains six genes encoding Class B PBPs which, like class A PBPs, contain a $\mathrm{C}$-terminal domain with transpeptidase activity. The $\mathrm{N}$-terminal domain of Class B PBPs has an unknown, non-catalytic function. The best studied protein in this class is the essential E. coli PBP3, which functions in cell-division (see Errington et al., 2003). Here, the N-terminal domain is important for protein folding and stability (Goffin et al., 1996) and for the recruitment of other cell division proteins (Wissel and Weiss, 2004). The crystal structure of the Class B PBP2x from Streptococcus pneumoniae showed that the $\mathrm{N}$-terminal domain resembles a sugar tong, but structural homologues have not been found in the databases (Parès et al., 1996) so the function of this domain is still enigmatic. It has been proposed that this domain plays a role as a morphogenetic determinant, as some of the Class B PBPs have a specific role in cell wall synthesis during either division or elongation (Goffin and Ghuysen, 1998). PBP2b, the homologue of $E$. coli PBP3, is the only essential PBP in $B$. subtilis, functions in cell division and is expressed during vegetative growth and sporulation (Yanouri et al., 1993). Interestingly, it is the presence but not the catalytic activity of PBP2b which is essential (Morales Angeles et al., 2017), and PBP3 becomes an essential TPase when PBP2b is catalytically inactive (Sassine et al., 2017). Modelling of the interaction between DivIB and PBP2b suggests that it is not the N-terminal domain, but rather the TPase domain of PBP2b that contacts DivIB, the protein that recruits PBP2b to the septum (Rowland et al., 2010). In addition, the PASTA (Penicillin binding protein And Serine Threonine kinase Associated) domains of PBP2b play a role in strengthening the interaction between PBP2 $b$ and DivlB (Morales Angeles et al., 2020). PBP2a and $\mathrm{PbpH}$ are expressed during vegetative growth and play redundant roles in cell wall growth during elongation: a double mutant of these PBPs is not viable and depletion of one in the absence of the other leads to swelling of the cells and eventually to lysis (Wei et al., 2003). SpoVD is expressed during sporulation (Daniel et al., 1994a) and is responsible for PG synthesis during engulfment and synthesis of the spore cortex PG (Bukowska-Faniband and Hederstedt, 2013). The remaining two PBPs, PBP3 and PBP4b, are expressed during vegetative growth and sporulation, respectively, and have unknown functions (Murray et al., 1996; Wei et al., 2004). The recent discovery that SEDS proteins function together with a cognate Class B PBP (Sjodt et al., 2020; Taguchi et al., 2019) strongly suggests that the SEDS/PBP pairs in $B$. subtilis are FtsW/PBP2b, SpoVE/SpoVD, and RodA/PBP2a/H. However, there are also questions: Does RodA indeed associate with both PBP2a 
and $\mathrm{PbpH}$, as the functional redundancy of those PBPs (Wei et al., 2003) suggests? And if PBP2b presence is sufficient for FtsW activity (Taguchi et al., 2019) then how can PBP3 join this assembly to take over the TPase functionality from PBP2B (Sassine et al., 2017)? And what is the role of the Class B PBPs that are not thought to be associated with a SEDS partner?

The Low MW PBPs can be subdivided in two classes: carboxypeptidases, of which $B$. subtilis has four, and endopeptidases, of which $B$. subtilis has two. PBP5 is the major D,D-carboxypeptidase, and in a PBP5 deletion strain, the terminal DAla residues are not removed from pentapeptide side chains that either were not crosslinked or functioned as acceptors during transpeptidation (Atrih et al., 1999), which is also true for the fluorescent D-amino acid analogue HADA, which is incorporated in position 5 of the stem peptide and a substrate for PBP5 (Kuru et al., 2012) (Figure 4B). PBP5* has been shown to function as a D,Dcarboxypeptidase during sporulation (Buchanan and Ling, 1992; Todd et al., 1985). Together with DacF, PBP5* regulates the degree of crosslinking in spore cortex PG (Popham et al., 1999). The final carboxypeptidase, PBP4a, is expressed during late stationary phase (Pedersen et al., 1998) and is capable of catalyzing peptidation reactions on mDAP both with and without an amidated Ncarboxylic acid (Nemmara et al., 2013). Classically, D,D-carboxypeptidases are thought to play a role in PG maturation, cleaving off terminal D-Ala residues from stem peptides after transpeptidation. However, it is also possible that these proteins control the length of the stem peptides that function as substrate for transpeptidation, thereby controlling substrate availability for Class B PBPs with different morphogenetic properties (see below). The endopeptidases in $B$. subtilis were assigned on the basis of their homology to the known $E$. coli endopeptidase PBP4 (Korat et al., 1991), but both PBP4*, which is expressed during sporulation, and $\mathrm{PbpX}$, which is expressed during vegetative growth, can be lost through deletion of the genes without any phenotypic effects (Popham and Setlow, 1993b; Scheffers, 2005).

\section{Structure of PBPs}

The transpeptidase domains of both Class A and B HMW PBPs contain conserved motifs that constitute the unique signature of all penicillin interacting proteins: SXXK, with the active site serine, $(\mathrm{S} / \mathrm{Y}) \mathrm{XN}$ and $(\mathrm{K} / \mathrm{H})(\mathrm{T} / \mathrm{S}) \mathrm{G}$. These motifs are always present in the same order with similar spacing in the primary protein structure, forming the active site in the tertiary structure of the domain (Ghuysen, 1991; Goffin and Ghuysen, 1998; Massova and Mobashery, 1998).

The crystal structures of several high and low molecular weight PBPs from various organisms have been determined in the last few years (for an overview see Mattei et al., 2010; Miyachiro et al., 2019; Sauvage and Terrak, 2016). TP domains show high similarity, with a central, mixed, $\beta$-sheet surrounded by $\alpha$ helices. The structure of E. coli PBP6 in complex with a MurNAc-pentapeptide substrate revealed that the D-Ala-D-Ala part of the peptide is positioned within the active side cleft with the rest of the substrate accessible to the solvent, leaving the third stem peptide residue free to participate in a TP reaction (Chen et al., 2009). The crystal structure of a soluble form of $S$. pneumoniae PBP1b revealed a 
A

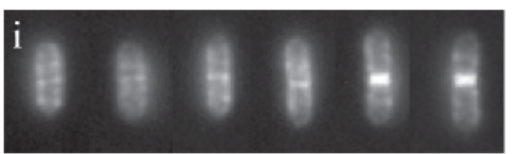

B

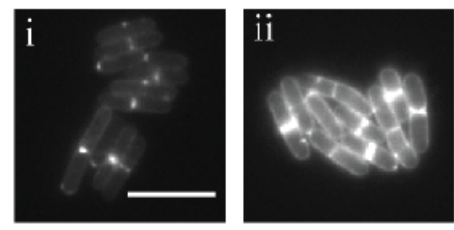

$\mathrm{C}$

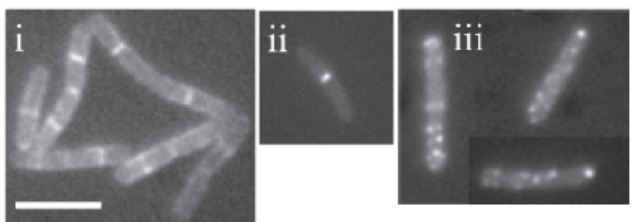

D

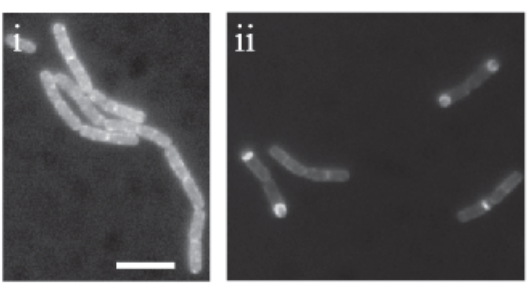

E

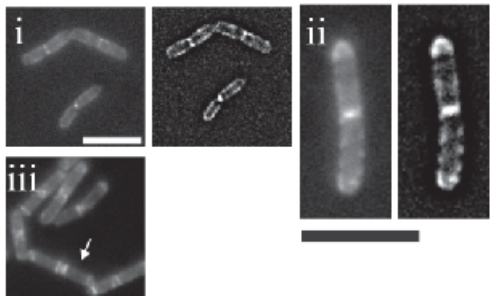

G

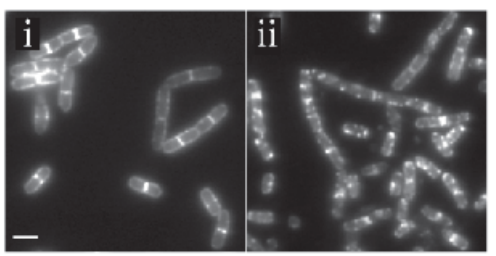

Figure 4. Localisation of PG precursor insertion and PBPs in B. subtilis. (A) Van-FL staining of nascent PG during various stages in the cell cycle in a wild-type strain (adapted, with permission from Elsevier, from Daniel and Errington, 2003). (B) HADA staining of $B$. subtilis wild type (i) and $B$. subtilis $\triangle$ dacA (ii)(DMA, unpublished). (C) Representative patterns for PBP distribution: (i) disperse, shown is GFP-PBP2a; (ii) septal, shown is GFP-PBP1; (iii) spotty, shown is GFP-PBP3 (adapted, with permission from Blackwell Publishing, from Scheffers et al., 2004). (D) Redistribution of GFP-PBP2d during sporulation: (i) disperse localisation of GFP-PBP2d during vegetative growth; (ii) GFP-PBP2d localisation to the prespore membrane, 2 hours after resuspension in sporulation medium (adapted, with permission from SGM, from Scheffers, 2005). (E) Redistribution of GFP-PbpX during sporulation. (i, ii) GFP-PbpX localisation changes from a septal to membrane localisation (i) and appears to spiral out (ii, note difference in magnification) to both asymmetric division sites (iii). Right hand panels in (i) and (ii) show the images after deconvolution (adapted, with permission from SGM, from Scheffers, 2005). (G) PP- nisin delocalizes Lipidll and specific PBPs. GFP-PbpH localisation in untreated cells (i) and after treatmeant with PP-nisin (ii) (adapted with permission from Blackwell Publishing, from Lages et al., 2013). Scale bars: $5 \mu \mathrm{m}$ (A-F) $2 \mu \mathrm{m}$ (G). 
conformational change upon ligand binding (Macheboeuf et al., 2005). The active site of the transpeptidase domain of PBP1b was found to exist in an 'open' and 'closed' conformation, and the open conformation was dependent on the presence of ligand, whereas the closed conformation showed blocked substrate accessibility. The difference between the structures suggests that PBPs may be activated by the availability of transpeptidation substrate, as the 'open' conformation could only be obtained by soaking crystals containing the 'closed' form of PBP1b with a stem peptide analogue (Macheboeuf et al., 2005). Similar local flexibility has been confirmed in a number of other structures, and is linked to the development of resistance to $\beta$-lactam antibiotics, see (Mattei et al., 2010). Another example of flexibility is $S$. pneumoniae PBP2x, which is a TPase that has two PASTA domains at its C-terminus. These PASTA domains form an allosteric binding site for a pentapeptide stem in a nascent peptidoglycan strand, which positions another stempeptide on the same strand in the active site so that it can be cross-linked (Bernardo-Garcia et al., 2018). Binding of the terminal D-Ala-D-Ala of the stempeptide at the allosteric site displaces a 'gatekeeper' Arginine residue on the transpeptidase domain, which results in the opening up of the active site so that the donor stempeptide for transpeptidation on the same glycan strand can bind (Bernardo-Garcia et al., 2018). PASTA domains are only present in a few PBPs, in $B$. subtilis on PBP2B and SpoVD, but there is no indication that this allosteric activation mechanism also works for $B$. subtilis PBPs (Morales Angeles et al., 2019).

Insight into TG domain structure has come from the structures of 2 Class A PBPs and two isolated TG domains, which display a lysozyme-like fold (Heaslet et al., 2009; Lovering et al., 2007; Sung et al., 2009; Yuan et al., 2007). Next to the TG and TP domains E. coli PBP1b contains an additional domain, UvrB domain 2 homolog $(\mathrm{UB} 2 \mathrm{H})$, which is required for the interaction of PBP1b with the lytic transglycosylase MItA and the lipoprotein LpoB that activates PBP1b (Markovski et al., 2016; Sung et al., 2009).

\section{Cell wall turnover}

The cell wall is subject to continuous turnover, with PG being hydrolyzed and synthesized at the same time. Autolysins, proteins that hydrolyse PG, play a role in various processes in $B$. subtilis, such as PG maturation, separation of the cell wall at the septum during division, motility, competence development, spore development, germination and protein secretion (for reviews see Smith et al., 2000; Vollmer et al., 2008). Hydrolysis activity must be tightly controlled to allow insertion of a PG strand in the meshwork without disrupting the structural integrity of the PG (especially in Gram-negative organisms because the PG is only 1 to 3 layers thick). Not much is known about the turnover of anionic polymers, but evidently, the PG linked WTA and teichuronic acid will be released from the cell wall when $P G$ is hydrolysed.

Genome analysis revealed the presence of 35 definite or predicted autolysins in B. subtilis that cluster in 11 different protein families (Smith et al., 2000). These proteins hydrolyse all the different bonds in PG: glucosaminidases LytD and LytG hydrolyse the bond between GIcNAc and MurNAc; muramidases (enterococcal 
muramidase family) and lytic transglycosylases (SIt70 family, germination specific lytic enzyme family) hydrolyse the bond between MurNAc and GlcNac; amidases (LytC family, XlyA family) cleave the bond between MurNac and L-Ala(1) on the stem-peptide and D,L-endopeptidases (families I and II) and L,D-endopeptidase cleave $D, L$ and $L, D$ peptide bonds in the stem peptides and crosslinks. Two additional protein families were identified. Firstly, proteins homologous to Lysostaphin, an endopeptidase that cleaves pentaglycine cross bridges occuring in Staphylococcus species but not in Bacillus, suggesting that these proteins may be secreted by Bacillus as antibiotics against staphylococci. Secondly, proteins homologous to $\mathrm{LrgB}$, a putative autolysin from $S$. aureus with no identified function.

During vegetative growth, about $95 \%$ of the autolyic activity is mediated by the amidase LytC and the glucosaminidases LytD and LytG. Inactivation of these autolysins, in various combinations with the D,L-endopeptidases LytE and LytF, and YwbG (LrgB family) results in formation of chains of cells indicating a role in cell separation (Blackman et al., 1998; Ishikawa et al., 1998; Margot et al., 1999; Margot et al., 1998; Ohnishi et al., 1999). LytG functions as an exoglucosaminidase that removes GlcNAc residues from glycan strands, resulting in glycan strands with MurNac at their non-reducing termini (Atrih et al., 1999; Horsburgh et al., 2003b). Interestingly, overproduction of the predicted endopeptidase PBP4* also causes chain formation (Zellmeier et al., 2003). Expression of LytC, $-D$ and $-F$ as well as of genes for flagellar motility and chemotaxis are under control of the transcription factor $\sigma^{D}$ (Helmann and $\left.P, 2002\right)$ and inactivation of LytC and LytD causes dimished swarming motility (Blackman et al., 1998; Margot et al., 1994; Rashid et al., 1995), suggesting that autolysins play an as yet unidentified role in motility.

$\mathrm{D}, \mathrm{L}-$-endopeptidases as LytF, LytE, and CwlO have a similar C-terminal sequence, but different $\mathrm{N}$-terminal domains which determine their localization in the cell and function (Hashimoto et al., 2012). While LytF is the principal endopeptidase involved in cell separation, LytE and $\mathrm{CwlO}$ are required during elongation. LytF localizes to the division site (Yamamoto et al., 2003) and poles (Hashimoto et al., 2012) and is mainly expressed during mid-exponential phase (Hashimoto et al., 2012). LytE localizes to the septum and poles, but also at the lateral wall in a helix-like manner (Hashimoto et al., 2012; Kasahara et al., 2016). And finally, CwlO localizes to the sidewall and is expressed during early exponential phase (Hashimoto et al., 2012). LytF localization is affected by the presence of WTA and LTA. LytF loses it septal localization when the teichoic acids are depleted (Kiriyama et al., 2014; Yamamoto et al., 2008), but also the presence of LTA and WTA regulates the expression of the LytF transcription factor $\sigma^{\mathrm{D}}$.

LytE and $c w / O$ knockouts are viable, but a double deletion of $l y t E$ and of $c w / O$ is lethal indicating that the have similar function (Bisicchia et al., 2007). Interestingly, LytE interacts with MreBH (Carballido-López et al., 2006), while CwlO interacts with $\mathrm{Mbl}$ (Dominguez-Cuevas et al., 2013) two of the three actin homologues in $B$. subtilis. LytE and CwIO expression is regulated by the WalRK two component signal transduction pathway. LytE expression is upregulated under stress 
conditions like heat shock and high temperatures (Huang et al., 2013; Salzberg et al., 2013; Tseng et al., 2011), and again the presence of LTA or WTA play a role as LytE transcription is enhanced in the absence of LTA and WTA (Kasahara et al., 2016). CwlO is also controlled by WalRK but has highly instable transcript, so that the levels of CwlO will decrease quickly after WalRK deactivation, allowing a tight regulation of CwIO (Noone et al., 2014). Recently, Rudner and colleagues showed that WalRK sense PG cleavage products generated by LytE and CwIO, thus upregulating their activity when cleavage activity is low, and downregulating when cleavage activity is high (Dobihal et al., 2019). CwlO is also regulated at the protein level by the $A B C$ transporter FstEX. FstEX has been related to cell division in E. coli (Yang et al., 2011), however in B. subtilis it is involved in cell elongation. FtsE mutants with a defect in binding or hydrolysis of ATP are lethal in a lytE knockout background, strongly suggesting that FtsEX activity, probably through an ATP-mediated conformational change, is required to activate CwIO (Meisner et al., 2013).

Autolysins also play critical roles during spore formation and germination. The autolysins SpolID and SpolIP form a complex with the membrane protein SpollM that drives membrane migration during engulfment (Abanes-De Mello et al., 2002; Chastanet and Losick, 2007). In addition SpolID and SpollP degradation activity at the septum allows the recruitment of SpollIAH and SpollQ to the sporulation septum (Rodrigues et al., 2013). The amidase CwID (see above, LytC family) is involved in the generation of muramic- $\delta$-lactam, which is recognized by lytic enzymes that break down the spore cortex during germination (Atrih et al., 1996; Popham et al., 1996; Sekiguchi et al., 1995). During maturation of the spore cortex, stem peptides of non crosslinked muramic acid residues are generally cleaved to single L-Ala residues by the action of $\mathrm{LytH}$, a proposed L,Dendopeptidase, which is homologous to lysostaphin (Horsburgh et al., 2003a). Release of spores occurs through lysis of the mother cell, which involves LytC, CwIC and CwlH (Nugroho et al., 1999; Smith and Foster, 1995). Spore germination requires the action of the partially redundant autolysins SleB and CwlJ (Chirakkal et al., 2002).

Since autolysins can disrupt the integrity of the PG structure, and therefore are potentially lethal, their activity needs to be under tight control. Little is known about this aspect, but it has been suggested that the energy state of the cell, through the proton motive force (pmf), controls aulolysin activity. The cell wall of $B$. subtilis is protonated (and thus acidic) under respiring conditions (Calamita et al., 2001) and dissipation of the pmf renders cells more sensitive to lysis (Jolliffe et al., 1981; Jolliffe et al., 1983; Kemper et al., 1993). This suggests that when the acidity of the cell wall decreases, the activity of autolysins increases, resulting in cell lysis. Exciting work based has provided evidence for activation of cell wall hydrolases by other cell wall binding or degrading proteins: in $E$. coli, cell wall binding proteins EnvC and NIpD activate the amidases AmiA, $-B$, and $-C$ at the cell division site and thus control cell separation (Uehara et al., 2010), whereas in $B$. subtilis SpollP cleaves stem peptides and activates the lytic transglysolyase SpolID to remove PG during prespore engulfment (Morlot et al., 2010). The molecular details of these activation mechanisms are beginning to be elucidated 
with the help of crystal structures (Nocadello et al., 2016). Finally, the cleavage products generated by LytE and CwIO are sensed by the WalRK two component singaling pathway, which regulates the expression of $l y t E$ and $c w / O$ (Dobihal et al., 2019).

Although turnover of cell wall material has been studied for some time in Gramnegatives, the observation of large amounts of PG fragments shed by Grampositives combined with the notion that the thick cell wall is degraded on the outside and thus fragments are free to diffuse, has for a long time led people to think that Gram-positives do not recycle their cell wall fragments (Johnson et al., 2013; Reith and Mayer, 2011). The Mayer group discovered a recycling pathway in $B$. subtilis that contains several genes that are homologous to Gram-negative recycling genes (Litzinger et al., 2010). Muropeptides released by autolysins are further processed in the 'cell wall compartment' on the outside of the cell to GlcNAc and MurNAc by the activites of NagZ and AmiE, and transported into the cytoplasm by the phosphotransferase systems NagP and MurP. Then, in the cell, the recycling enzyme MurQ converst MurNAc-6P to GlcNAc-6P, which can be reused. The released peptide fragments are likely to be taken up by Oligopeptide transport systems (Johnson et al., 2013; Reith and Mayer, 2011). Reusing peptidoglycan fragments makes sense, not only from an energetic point of view, but also in cases where eg pathogens or symbionts do not want to overstimulate the hosts' immune system by the release of large amounts of peptidoglycan fragments. In addition, peptidoglycan fragments are used by bacteria to sense damage to the cell walls and stimulate the expression of $\beta$-lactamases to counteract the activity of antibiotics (Johnson et al., 2013).

\section{Organisation of cell wall synthesis in Bacillus subtilis.}

The use of fluorescence microscopy, AFM and ECT has allowed new studies on the insertion of material into the cell wall, the architecture of the cell wall, the visualisation of cytoskeletal elements, as well as localisation studies on the proteins involved in cell wall synthesis. B. subtilis has played a leading role in these studies: it was the first bacterium for which Errington and co-workers (i) identified an actin-like cytoskeleton (Jones et al., 2001) (ii) obtained high resolution images of localised PG precursor insertion along the lateral wall (Daniel and Errington, 2003) and (iii) generated a comprehensive data-set on PBP localisation (Scheffers et al., 2004). Also, B. subtilis was one of the first bacteria for which the PG architecture was studied by AFM (Hayhurst et al., 2008) and cryotomography (Beeby et al., 2013).

\section{Two modes of cell wall growth in rod shaped bacteria}

Cell wall synthesis in rod-shaped bacteria like $B$. subtilis is thought to occur in two modes: one associated with elongation of the cell, and one associated with cell division. This is in contrast to cell wall synthesis in spherical cocci, which takes place only at the division site, or in 'rugby-ball' shaped Streptococci that synthesize the cell wall at the septum and the so-called 'equatorial rings' (Turner et al., 2014). The concept of lateral wall growth vs. division wall growth originates from the observation that various mutations in genes associated with cell wall synthesis in $B$. subtilis and $E$. coli block either elongation of the cells (lateral 
growth) or cell division. An elongation block leads to cells that loose shape control and start to grow as spheres and eventually lyse. On the other hand, a division block leads to filamentation and eventually lysis. In a classic paper, Spratt described Class B transpeptidases from $E$. coli specific for elongation (PBP2) or for division (PBP3) (Spratt, 1975). Similarly, B. subtilis contains a division specific Class B PBP, PBP2b (Yanouri et al., 1993), and two Class B PBPs, PBP2a and $\mathrm{PbpH}$, involved in elongation (Wei et al., 2003). PBP1 is a Class A PBP that shuttles between cell division and elongation(Claessen et al., 2008). Growth defects of the lateral wall are also observed in mutants of the SEDS transglycosylase RodA in both E. coli and B. subtilis (de Pedro et al., 2001; Henriques et al., 1998), whereas mutations in the division-specific SEDS FtsW transglycosylase result in filamentation (Boyle et al., 1997). Cells with a deficiency in WTA synthesis grow as spheres, underscoring the role of the anionic cell wall polymers in shape maintenance in Gram-positive cells (D'Elia et al., 2006a; Pollack and Neuhaus, 1994; Pooley et al., 1992).

Cell wall synthesis and turnover involve biochemical reactions that are catalysed by different enzymes. The observation that labelled PG precursors are incorporated close to the membrane in Gram-positives and are gradually displaced within the wall to the outside led Koch and Doyle to propose the 'insideto-outside' model for cell wall growth (Koch and Doyle, 1985). In this model, new material is inserted close to the membrane where the PBPs are, and are displaced outward as a result of the incorporation of new material. On moving out, the PG is stretched and becomes stress bearing, but also more susceptible to the activity of autolysins. Continuous synthesis of PG close to the membrane prevents the cell wall from rupturing, according to what is called the 'make-beforebreak' principle (Koch, 2000). As an extension to this model the existence of multienzyme complexes involved in cell wall synthesis was proposed by Höltje, originally for $E$. coli (Höltje, 1996, 1998). The multi-enzyme complexes ensure the coordinated activity of incorporating new material into the wall without compromising cell wall integrity, which is extra critical in Gram-negative cells that contain only 1 to 3 layers of continuous PG (Höltje, 1998; Turner et al., 2014; Typas et al., 2012). These complexes would combine transglycosylase, transpeptidase and PG hydrolysis activities and could allow for controlled insertion of glycan strands into an existing PG meshwork while simultaneously removing old material.

The discovery of bacterial cytoskeletal proteins and their influence of cell shape (Margolin, 2009) strongly suggested that positioning and activity of the multienzyme complexes that synthesize the cell wall is controlled by the cytoskeleton (Figure 5). FtsZ, the bacterial homologue of tubulin, positions all cell division proteins at midcell and is required for the correct synthesis of the division septum. The actin homologue MreB, of which $B$. subtilis contains three paralogues (MreB, $\mathrm{Mbl}$ and $\mathrm{MreBH}$ ), is similarly responsible for positioning of the cell wall synthesis machinery during elongation. Localisation and interaction studies in various bacteria have provided strong evidence for this hypothesis, even though it is not resolved whether both models are completely separate and whether simultaneous cell wall synthesis at both sites can occur. 


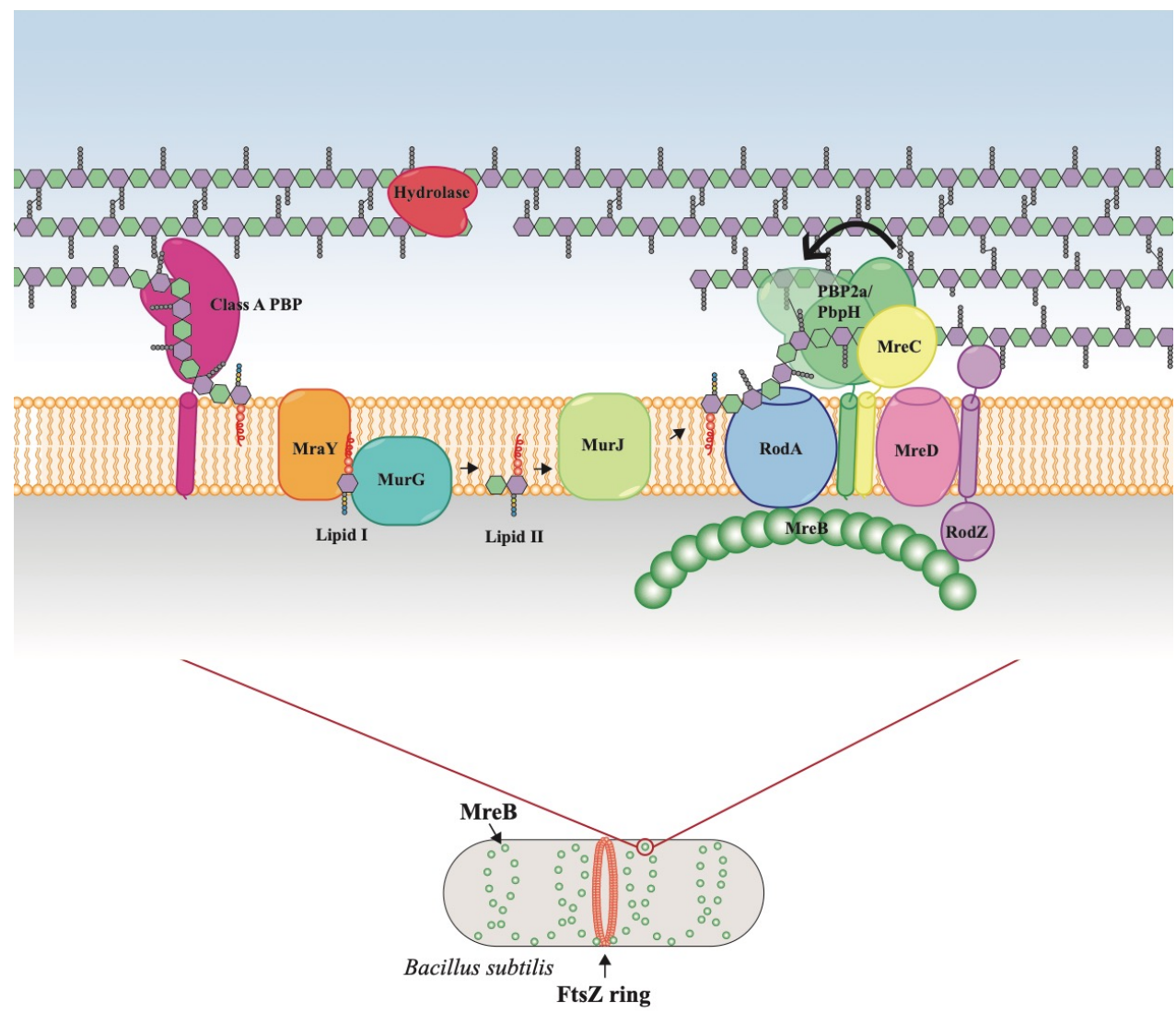

Figure 5. Putative enzyme complexes functioning in cell wall synthesis in Bacillus subtilis. Depicted is a complex involved in growth of the lateral cell wall during elongation. The actin-like cytoskeletal protein MreB or $\mathrm{Mbl}$ (green, cytosolic) organises the localisation of the SEDS/class B PBP pair RodA/PBP2a (or PbpH). MreC binds the bPBP and modulates its activity, while MreD and RodZ are also part of the complex. MraY interacts with MurG to produce Lipid II which is translocated via MurJ (or a homologue). The Lipidll, after translocation, is either incorporated into PG via the SEDS/class B PBP pair to provide directed growth, or via a Class A PBP that aides to repair gaps in PG. Autolysins and hydrolases mediate cell wall turnover. During cell division, the cytoskeletal protein would be FtsZ and the SEDS/Class B PBP pair is FtsW/PBP2b.

\section{Cell wall synthesis during division.}

Cell division starts with the assembly of the Z-ring, formed by polymers of the tubulin homologue FtsZ (Adams and Errington, 2009; Meier and Goley, 2014; Rowlett and Margolin, 2015). After assembly of the Z-ring, all other cell division proteins, including the division specific PBP2b localise to the division site and synthesis of the septum follows. In both $B$. subtilis and $E$. coli, the rate of $P G$ synthesis during cell division is notably increased compared to synthesis during cell growth along the lateral wall (Cooper and Hsieh, 1988; Daniel and Errington, 2003; de Pedro et al., 1997; Kuru et al., 2012; Woldringh et al., 1987). MurG, the last enzyme in the Lipidll synthesis pathway, localises to the division site 
depending on FtsZ in both E. coli and C. crescentus (Aaron et al., 2007; Mohammadi et al., 2007). Several PBPs in B. subtilis show specific localisation to the division site: PBPs 1, 2b and PbpX (Scheffers et al., 2004). More recently, it has been shown in Bacillus that FtsZ treadmilling determines the motion of septal $P G$ enzymes. Furthermore, the PG rate synthesis and its distribution are also controlled by the rate of FtsZ treadmilling (Bisson-Filho et al., 2017). Although it has been speculated that FtsZ provides the driving force for constriction, recent work in $S$. aureus revealed that FtsZ is required for the initiation of division, but that cells can complete PG synthesis driven division and separation in a FtsZindependent manner (Monteiro et al., 2018). Thus, PG synthesis is not simply required to generate material for the new cell poles, but is a driving force of the division process.

PBP2 $b$ is the cell division specific transpeptidase and the only essential PBP in $B$. subtilis - $p b p B$ mutants form long filaments, the characteristic cell division mutant phenotype. PBP2b interacts with cell division DivIB as determined by a two-hybrid assay and a heterologous targeting assay (Daniel et al., 2006; Robichon et al., 2008; Rowland et al., 2010). Inactivation of the active site of PBP2B does not affect viability, nor have evident effects on the phenotype of cells (Morales Angeles et al., 2017; Sassine et al., 2017), however PBP3 becomes essential in the absence of PBP2B (Sassine et al., 2017). A PbpX deficient strain has no observable phenotype (Scheffers, 2005). A role for PBP1 in cell division had been postulated on the basis of the phenotype of a PBP1 deficient strain, which grows at a reduced rate, has slightly elongated cells, less efficient spore formation (Popham and Setlow, 1996) as well as abnormal septal structures (Pedersen et al., 1999). The sporulation deficiency in the PBP1 mutant is the cause of a defect in the formation of the asymmetric sporulation septum. Also, the localisation of GFP-PBP1 depends on the presence of other membrane-associated cell division proteins (all membrane bound cell division proteins in $B$. subtilis are interdependent in terms of localisation, see Errington et al., 2003), more specifically EzrA (Claessen et al., 2008). It has become evident that PBP1 is also involved in lateral wall growth and shuttles its localisation from the division site to the lateral wall, where it is bound by MreB (Kawai et al., 2009b), through the interaction with GpsB (Claessen et al., 2008). GpsB is a $\sim 10 \mathrm{kDa}$ membrane associated protein, conserved in Gram-positives. Furthermore, there is evidence that phosphorylation might be involved in the regulation of PBP1, GpsB and cell wall synthesis. PrkC belongs to a family of serine/threonine-kinases that have been associated with regulation of cell wall synthesis and cell division (Manuse et al., 2016). In Bacillus, PrkC interacts with GpsB, DivIVA and Ezra, however only GpsB interacts with the active site of PrkC. PrkC and GpsB interact to control each other: on the one hand, PrkC phosphorylates GpsB at Thr75, while on the other hand PkrC auto-phosphorylation is stimulated by unphosphrylated GpsB, and inhibited by phosphorylated GpsB (Pompeo et al., 2015). The link between Gpsb phosphorylation and PBP1 is not clear - both proteins interact in vitro, but the in vitro glycosyltransferase and transpeptidase activity of PBP1 are not affected by either GpsB or a phosphomimetic GpsBT57D/E mutant (Cleverley et al., 2016; Rismondo et al., 2016), suggesting that GpsB does not influence the enzymatic activity of PBP1. A possibility is that phosphorylation might be related 
with the shuttling of PBP1 from the division site to the lateral wall. Interestingly, another protein phosphorylated by PrkC has proven to have an effect in PBP1 localisation. YvcK is a protein essential for growth under gluconeogenic condition (Gorke et al., 2005). PrkC phosphorylates YvcK at Thr304 and PrpC dephosphorylates YvcK. In the absence- of MreB, overproduction of YvcK restored PBP1 localization and the MreB phenotype. Furthermore, only the overproduction of a phosphomimetic version of Yvck (T304E) in the absence of MreB rescued the characteristic bulging phenotype, while the phosphoablative version (T304A) did not (Foulquier et al., 2014).

A Native PAGE analysis of $E$. coli membranes revealed a complex containing a number of cell division proteins including $\mathrm{Fts} Z,-\mathrm{Q},-\mathrm{L},-\mathrm{B}$, and $-\mathrm{N}$, but no PBPs (Trip and Scheffers, 2015). A recent pull down in B. subtilis with a Lipidll analogue containing a photocrosslinker identified PBPs 1, 3, 4, 5 and $X$ bound to Lipidll next to several other known cell wall synthesis and division proteins (EzrA, LytE, MurG, FtsX among others) (Sarkar et al., 2016).

The housekeeping LTA synthase LtaS $_{\mathrm{BS}}$ also localises to the division site and ItaS mutants have a reduced diameter and aberrantly formed septa, suggesting that LTA may be specifically synthesized and localised at the cell division site (Schirner et al., 2009).

The material that is synthesized at the division septum will form one of the two cell poles of each daughter cell after separation. These poles are called the 'new' poles, as opposed to the 'old' poles that are the poles from the mother cell. In $E$. coli, the cell wall at the poles is 'inert', i.e. no new material is inserted at these sites, and polar PG is not subject to degradation/turnover, in contrast to material in the lateral wall (Burman et al., 1983; de Pedro et al., 1997). Cell wall turnover at the poles in $B$. subtilis is very slow, but insertion of new material at the poles does occur (Graham and Beveridge, 1994; Mobley et al., 1984). Also, the use of FDAAs revealed that the PG synthesized at the division site is enriched in pentapeptide stem, indicating a lower degree of cross-linking and/or processing. After division, this material is slowly processed (Morales Angeles et al., 2017). Whether this difference between $E$. coli and $B$. subtilis with respect to the insertion of material at the poles is a true difference between these organisms or the result of different experimental approaches is unclear. The cause for the (virtual) absence of cell wall turnover at the cell poles is not known but may be caused by a difference in structural PG composition at the pole compared to the lateral wall or the presence/absence of proteins involved in PG turnover at the poles. One of these proteins is MinD, part of the Min machinery that prevents division at the poles, which (in)directly restricts PG remodeling at cell poles (Yu et al., 2020). The poles of rod-shaped cells constitute an area of restricted mobility for periplasmic proteins (Foley et al., 1989) and for outer membrane proteins (de Pedro et al., 2004; de Pedro et al., 2003). Strikingly, an E. coli mutant for the major D,Dcarboxypeptidase PBP5 displays a branching phenotype. The branches originate from areas of inert PG in the lateral wall that are thought to act as de novo poles from which the branches originate (de Pedro et al., 2003; Gullbrand et al., 1999). 


\section{Cell wall synthesis during elongation}

Initial studies on the incorporation and turnover of cell wall material at the lateral wall used labelled PG precursors (mostly GlcNAc). Old wall material was found to co-segregate with DNA and new material was inserted in patches (Pooley et al., 1978; Schlaeppi and Karamata, 1982; Schlaeppi et al., 1985). Cell wall material is turned over rapidly at the cell cylinder but is retained at the cell poles, so that polar material is conserved for several generations, although some insertion of new material does occur at the poles (Mobley et al., 1984). A study using phage SP50 as a marker for teichoic acid synthesis (SP50 binds specifically to TA containing bacteria) showed that TA becomes exposed at the lateral wall first and then migrates towards the poles, but that new material is incorporated along the entire wall, and thus also at the cell poles (Clarke-Sturman et al., 1989). Teichoic acid is only accessible from the outside at discrete places along the cylinder, at division septa or at the junction between the cell pole and the cylinder, possibly indicating areas of high hydrolytic activity (Graham and Beveridge, 1994).

Daniel and Errington developed a method to visualise cell wall synthesis in $B$. subtilis using a fluorescent derivative of vancomycin (Daniel and Errington, 2003). The antibiotic vancomycin binds to the terminal D-Ala-D-Ala of PG precursors and thus blocks transpeptidation. In control experiments it was shown showed that Van-FL binds to externalized but unincorporated lipid-linked PG precursors and to the recently inserted lipid-linked subunit at the growing end of a glycan strand, and can therefore be used as a marker for nascent PG synthesis. Removal of the terminal D-Ala by the action of transpeptidases or carboxypeptidases precludes Van-FL binding, therefore older PG will not be labelled (Daniel and Errington, 2003). Van-FL does not penetrate the outer membrane of Gram-negative cells and can therefore only be used to label Gram-positives. Van-FL staining of growing $B$. subtilis cells showed prominent staining at an area around the division site, corresponding to areas of high PG synthesis activity observed with radiolabelled PG precursors. No staining was observed at the cell poles, showing that cell wall turnover at the poles is absent or very low. Although less bright, the staining pattern at the lateral wall could be resolved to follow a helical pattern. The helical pattern of PG insertion was confirmed in an independent study by the Walker and Rudner groups, who developed fluorescent derivatives of vancomycin and ramoplanin, which binds to the reducing end of a nascent glycan chain as well as to Lipid II (Tiyanont et al., 2006). The use of Van-FL in other Grampositives revealed polar growth in hyphal growth of Streptomyces coelicolor. Corynebacterium glutamicum, which grows in a rod-like shape but lacks a homologue of MreB, grows both at the division site and at the poles (Daniel and Errington, 2003). These results illustrate the different growth modes of rod-shaped organisms that either contain or lack MreB-like proteins (see Carballido-López, 2006).

More recently, the ability of bacteria to incorporate D-amino acids different than Dala into the stem peptide, has been used by several groups to developed fluorescent (FDAAs) and clickable analogues of D-amino acids (Kuru et al., 2012; Kuru et al., 2015; Shieh et al., 2014; Siegrist et al., 2015; Siegrist et al., 2013) that can be visualised in real time by microscopy or further analysed by HPLC and 
Mass spectrometry. In contrast to Van-FL labelling, FDAAs are incorporated into the stem peptide and can be used in gram negatives without the need to permeabilize the outer membrane.

Interestingly, FDAAs are incorporated only at the 5th position in the stem peptide of Bacillus, while in other bacteria, such as $E$. coli they are incorporated at position 4 (Kuru et al., 2012). The difference of the position at which FDAAs are incorporated into the stem peptides reflects the mechanism of how D-amino acids are incorporated into the cell wall. It has been reported that $E$. coli and $P$. aeuruginosa incorporate D-amino acids in the 4th position via an amino acid exchange reaction by L,D-transpeptidases (Ldts). In contrast, B. subtilis, $E$. faecalis and $S$. aureus incorporate D-amino acids in position 5 . Incorporation in 5th position is performed by D-alanyl-D-alanine ligase (Ddl) which is part of Lipidll synthesis. Interestingly, when Ddl was inhibited with D-cycloserine in B. subtilis no effect was observed in the incorporation of some non-canonical D-amino acids suggesting a different mechanism (Cava et al., 2011) for amino acids that are normally not substrates for Ddl.

$B$. subtilis has the D-carboxypeptidase PBP5 that removes the last D-ala of the stem peptide (Atrih et al., 1999), and PBP5 also removes FDAAs that are incorporated at the 5th position reducing overall labelling (Kuru et al., 2012). Fura and collaborators (2015) (Fura et al., 2015) tested the ability of all Bacillus PBPs with transpeptidation activity to incorporate fluorescently labelled D-Lysine analogues into the cell wall. Most of the PBPs showed a minor effect in labelling, however a PBP4 knockout had an significant decrease in labelling. Interestingly, signal at the division site was observed in all strains, which could indicate that FDAAs at the septum are incorporated via the Lipid II pathway rather than transpeptidation.

The helical patterns for PG insertion closely matched the helices formed by the bacterial actin homolog MreB. B. subtilis contains three paralogues of MreB: $m r e B$, which forms an operon with $m r e C$ and $m r e D, m b l$ and $m r e B H$, and all three paralogs have a role in ensuring corect cell shape as mutants lose their rod shape (Abhayawardhane and Stewart, 1995; Defeu Soufo and Graumann, 2003; Jones et al., 2001; Levin et al., 1992; Varley and Stewart, 1992). The importance of $m r e B$ is underscored by the fact that it is essential in many bacteria, like $B$. subtilis (Formstone and Errington, 2005), E. coli (Kruse et al., 2005), C. crescentus (Figge et al., 2004), or Rhodobacter sphaeroides (Slovak et al., 2005). Also, expression of $B$. subtilis $m r e B$ in $E$. coli leads to an altered cell morphology (Defeu Soufo and Graumann, 2010). Similarly, both $m r e C$ and $m r e D$ are essential in $B$. subtilis and in E. coli, and depletion of each results in spherical cells (Kruse et al., 2005; Leaver and Errington, 2005; Lee and Stewart, 2003).

All MreB paralogs are part of a helical structures in B. subtilis, which undergo. continuous assembly/disassembly, most likely through treadmilling (CarballidoLópez and Errington, 2003; Defeu Soufo and Graumann, 2004; Kim et al., 2006). Recent observations suggest that MreB orientation depends on the difference between the membrane curvatures. MreB is able to align to the largest curvatures 
most likely because the energy is minimized (Hussain et al., 2018). Furthermore, Bacillus can regulate the speed of MreB patches depending on nutrient availavility and rate growth. The speed of MreB patches is faster when Bacillus is grown in a rich medium than in a poor medium (Billaudeau et al., 2017). Interestingly, the speed of MreB patches is also sensitive to the fluidity of the cytoplasmic membrane, which is controlled by the two flotillins FloA and FloT, and membrane fluidity is linked to growth medium composition (Bach and Bramkamp, 2013; Zielińska et al., 2020). Thus, it may be membrane fluidity rather than growth rate which controls MreB movement, by creating a favourable environment for LipidII which prefers more fluid membrane patches (Calvez et al., 2019; Zielińska et al., 2020).

All three MreB paralogues interact as shown by bimolecular fluorescence complementation (biFC) and crosslinking although they are not always colocalized (Defeu Soufo and Graumann, 2006; Kawai et al., 2009a). Single deletions of MreB paralogs are tolerated although in the case of $m r e B$ the medium has to be supplemented with high $\mathrm{Mg}^{+2}$ (Formstone and Errington, 2005), and the insertion of $P G$ precursors along the lateral wall is not affected in single deletions (Kawai et al., 2009a). Double mutants, except the $\mathrm{mbl} m r e B H$ combination, are not viable (Defeu Soufo and Graumann, 2006), although a triple mutant can be constructed in the absence of the anti-sigma factor of ol (Schirner and Errington, 2009). When $m r e B$ is depleted in a $\mathrm{mb} /$ knockout background, cells show a strong growth defect and lose PG precursor insertion along the lateral wall, indicating that $m r e B$ and $m b /$ have redundant functions and that either one is required for correct cell wall synthesis during elongation (Kawai et al., 2009a). The role of $\mathrm{MreBH}$ in cell shape organization is slightly different. MreBH positions LytE, one of the cell wall hydrolases, in a helical pattern, which suggests that $\mathrm{MreBH}$ is involved in cell wall turnover rather than synthesis (Carballido-López et al., 2006).

The obvious relation between $\mathrm{MreB} / \mathrm{Mbl}$ and cell wall synthesis suggested that $\mathrm{MreB} / \mathrm{Mbl}$ control cell wall synthesis during elongation by forming multi-enzyme complexes with cell wall synthesis proteins. MreB is a cytoplasmic protein, whereas PBPs have at best very short cytoplasmic tails, so the question was how connections between these proteins are made. MreC and MreD are membrane proteins that also form helical patterns and that are responsible for cell shape and PG-precursor insertion along the lateral wall, so they were obvious candidates to connect the MreB scaffold to cell wall synthesis proteins (Daniel and Errington, 2003; Kruse et al., 2005; Leaver and Errington, 2005). Other components of this multi-enzyme complex at the lateral wall would be MurJ, RodA and a class $B$ PBPs (such as the elongation specific PBPs $-2 a$ and $-\mathrm{H}$ ) required for incorporation of $P G$ precursors into glycan strands, as well as proteins involved in (lipo)teichoic acid synthesis. Very few PBPs actually localised in a helical pattern, nor was localisation of PBPs affected in mreB or $\mathrm{mbl}$ mutants (Scheffers et al., 2004), but increased resolution has shown that eg PBP1 does localise in a helical pattern (Claessen et al., 2008) in a MreB dependent fashion (Kawai et al., 2009b) and the redundancy of $m r e B$ and $m b /$ explains why localisation paterns were no affected in the absence of either MreB or Mbl. 
Evidence for the existence of multi-enzyme complexes came from two-hybrid studies and pull-down experiments. MreC is a dimeric protein with a single TM and a large periplasmic domain (van den Ent et al., 2006). Two-hybrid studies revealed that MreC interacts with all Class A and B PBPs (van den Ent et al., 2006) and with proteins involved in WTA synthesis, that also localise in a helical pattern (Formstone et al., 2008). Similarly, MreB was found to interact with several HMW PBPs in two-hybrid studies (Kawai et al., 2009b). In a pull down experiment using his-tagged $\mathrm{MreB}$ as bait, $\mathrm{MreC}$ and various fluorescently labelled PBPs (1, 2A, 2C and 4) could be copurified with MreB (Kawai et al., 2009b), and labelled PBPs (1, 2a and 4) were also copurified with his-tagged Mbl (Kawai et al., 2009b). This does not exclude the presence of other PBPs, as some PBPs are more abundant and/or more efficiently labelled in cell extracts therefore several PBPs present in the complex may be missed in these experiments. Also, the pull down experiments do not show that there is a direct interaction between PBPs and MreB/Mbl - there may be a bridging function for MreC. However, the two-hybrid and localization data do suggest that at least PBP1 and MreB interact directly (Kawai et al., 2009b). Another conserved protein that interacts directly with MreB was simultaneously discovered in $B$. subtilis, $E$. coli and C. crescentus (Alyahya et al., 2009; Bendezu et al., 2009; Shiomi et al., 2008). RodZ is a bitopic membrane protein with a cytoplasmic domain that adopts a helix-turn-helix structure that interacts with MreB (van den Ent et al., 2010). RodZ and MreB localisation is interdependent and inactivation of RodZ leads to shape defects. The bitopic structure of RodZ, with a cytoplasmic MreB binding domain and a large periplasmic/extracellular domain, make it another candidate for communicating structural information from MreB to a cell wall synthesis machinery, although the mislocalization of MreB in the absence of RodZ suggests that this communication is not a one-way process. It has been shown that MreB is important for RodZ stability and localization. Pull-down and Bacterial two-hybrid studies revealed interactions of RodZ with MreB, MreBH and Mbl, and with MreD. Surprisingly, a strain expressing only the cytosolic part of RodZ is rod shaped only when grown in the absence of $\mathrm{Mg}^{+2}$ and not with $\mathrm{Mg}^{+2}$, which normally stabilizes rod-shape in cells with defective cell wall synthesis (Muchova et al., 2013). This stabilization by $\mathrm{Mg}^{+2}$ is caused by the $\mathrm{Mg}^{+2}$-mediated inhibition of autolysins which is upregulated in cells with defects in PG synthesis, causing shape defects or lysis (Dajkovic et al., 2017).

More evidence for the possible existence of a complex comprising MreBCD and PBPs comes from studies in other organisms. E. coli MreC interacts with both MreB and MreD (Kruse et al., 2005). Immunoprecipitation of MraY showed interactions with MurG and MreB (Mohammadi et al., 2007). Earlier affinity studies using $E$. coli proteins involved in cell wall synthesis identified protein-protein interactions between bifunctional transpeptidase-transglycosylases PBPs, monofunctional transpeptidases, lytic transglycosylases, D,D-endopeptidases and structural proteins (Romeis and Holtje, 1994; Vollmer et al., 1999; von Rechenberg et al., 1996). In C. crescentus, MreB localises in a helical pattern that condenses into a ring at the cell division site, potentially to aid PG synthesis at midcell (Aaron et al., 2007; Figge et al., 2004; Gitai et al., 2004). PBP2 as well as 
several other PBPs were retained by $\mathrm{MreC}$ coupled to sepharose, again suggesting a direct role for MreC in PBP localisation (Divakaruni et al., 2005). An extensive two-hybrid analysis combined with localization studies showed that the cell wall synthetic complex contains MreB, MreD, MraY, MurB, MurC, MurE, MurF, MurG, RodA and RodZ (White et al., 2010). MreB and MreD localise interdependently in C. crescentus (White et al., 2010), whereas MreC and MreB localise independently (Divakaruni et al., 2005). Combined, these data make a strong case for a function of $\mathrm{MreD}$ in the localisation of (some) elongation-specific PBPs, and for MreB playing a scaffolding role. Also, MreB does not only play a role in cell shape determination, but also in other processes like chromosome segregation (for an overview see Gitai et al., 2005), which complicates the interpretation of mutant phenotypes.

Does MreB position PBPs directly? MreB dynamics require active PG synthesis in B. subtilis and E. coli (Dominguez-Escobar et al., 2011; Garner et al., 2011; van Teeffelen et al., 2011). In B. subtilis, PBP2A and PbpH, the PBPs essential for elongation in $B$. subtilis are drivers for MreB dynamics (Dominguez-Escobar et al., 2011; Garner et al., 2011). These observations led to the suggestion that MreB(like) polymers function by restricting the diffusion of PG synthesis complexes within the membrane rather than by actively positioning PBPs along a scaffold (Dominguez-Escobar et al., 2011; Garner et al., 2011). The MreB scaffold model was tested by analysis of the localization of PBP2A and PbpH in cells were MreB was delocalized by membrane depolarization, or Lipidll was delocalized by addition of the Lipidll clustering peptide nisin. The outcome of this test was that both PBPs, that are essential for MreB dynamics, localize to Lipidll, and do not delocalize when MreB is displaced (Lages et al., 2013), which supports the notion that MreB does not actively position PBPs.

\section{Cell wall synthesis during sporulation}

At the onset of sporulation, the two copies of the chromosome are deposited in a DNA structure that stretches the length of the cell, called the axial filament, and two polar division sites are formed, one of which develops into the sporulation septum. Asymmetric division triggers a developmental programme that is governed by mother cell and prespore specific transcription factors.

At the start of sporulation, a PBP of unknown function, $\mathrm{PbpX}$, spirals out from the medial division site to both asymmetric division sites during the switch from medial to asymmetric cell division at the start of sporulation (Figure 5D; Scheffers, 2005). This spiralling resembles patterns described for FtsZ, FtsA and EzrA (BenYehuda and Losick, 2002), and PbpX localises to both asymmetric division sites, whereas the division specific PBPs 2B and 1 only localise to the one site that has committed to form the sporulation septum (Scheffers, 2005). The function of PbpX is unclear, as a $p b p X$ deletion strain does not show cell division or shape defects in vegetative growth or in sporulation (Scheffers, 2005).

PBPs1 and 2b, which are both required for efficient formation of the asymmetric division septum once the polar division site has been selected, both localise to the polar division site (Daniel et al., 2000; Scheffers et al., 2004). Once the polar 
septum has been formed a process called engulfment starts, where the mother cell membrane migrates around the prespore and fuses at the cell pole to enclose the prespore within the mother cell. There is a special role for cell wall turnover and synthesis during this process. At the start of engulfment, the proteins SpollM, SpollD and SpollP assemble into a complex, anchored in the mother cell membrane, at the middle of the septum (Abanes-De Mello et al., 2002). After this localization, degradation of cell wall material at the septum is initiated to allow membrane movement and engulfment. SpollM is a membrane protein of unknown (scaffolding) function (Abanes-De Mello et al., 2002; Chastanet and Losick, 2007). SpollP is an amidase and endopeptidase that removes crosslinks and stempeptides from the septal PG. This allows SpollD to become active. SpollD is a lytic transglycosylase that acts on glycan strands without associated peptides. So SpolID needs SpollP to become active, but in a unknown fashion, SpollD also stimulates SpolIP activity. The result of these combined activities, is a PGdegrading complex that uses cell wall degradation to drive membrane migration around the prespore (Khanna et al., 2019; Morlot et al., 2010). However, not only $P G$ degradation is required for membrane migration during engulfment. Ramoplanin-FL staining of sites of PG synthesis during engulfment showed that there is active $P G$ synthesis at the leading edge of the engulfing membrane. Moreover, membrane migration is blocked when PG synthesis is blocked (Fay et al., 2010). This PG synthesis required the activity of SpoVD, a TPase that is essential for cortex synthesis (Daniel et al., 1994a) and that localises to the outer prespore membrane dependent on its putative cognate Lipidll translocase SpoVE (Fay et al., 2010). This leads to a model where degradation of PG that surrounds the entire cell functions as a track for membrane migration, which in turn is aided by the synthesis of new PG (the primordial cell wall) between the engulfing membrane (that will become the outer prespore membrane) and the inner prespore membrane (Meyer et al., 2010).

Once engulfment is complete, the spore cortex is synthesized between the outer and inner prespore membranes. This process requires SpoVD (above). Early studies on PBP profiles of sporulating $B$. subtilis indicated that PBPs $3,4^{*}$ and $5^{*}$ are involved in sporulation (Sowell and Buchanan, 1983; Todd et al., 1983). Transcriptional profiling and studies on mutant strains have now identified several other PBPs involved in sporulation. Two Class A PBPs, $2 \mathrm{c}$ and $2 \mathrm{~d}$ play redundant roles in sporulation (McPherson et al., 2001). PBPs $2 c$ and $2 d$ are under control of forespore specific transcription factors, with PBP2d being activated by both $\sigma^{F}$ (early factor) and $\sigma^{G}$ (late factor) and PBP2c being activated by $\sigma^{G}$. PBP2c is also present in the mother cell as it is also under the control of the vegetative transcription factor $\sigma^{\mathrm{A}}$ (McPherson et al., 2001; Popham and Setlow, 1993b). Interestingly, a GFP-fusion to PBP2c is stable in the mothercell, whereas a GFPfusion to PBP2d is not (Scheffers, 2005). Both GFP-PBP2c and 2d redistribute from the peripheral wall to the sporulation septum when expressed under control of $P_{x y l}$ (Figure 5D). From the septum, these proteins follow the mother cell membrane during engulfment and finally localise to the outer prespore membrane. This localisation pattern was also observed when either GFP-PBP2c or $2 \mathrm{~d}$ was expressed in the absence of PBP2d or $2 \mathrm{c}$, respectively, indicating that these proteins do not depend on each other for their localisation (Scheffers, 
2005). Even though PBP2c is not essential, it would be interesting to see whether it also aides in the membrane migration during engulfment, as SpoVD can only catalyse TP reactions. Other PBPs that have been found to act during sporulation, such as PBP4b (Eichenberger et al., 2003; Wei et al., 2004), PBP3 and PBP4* (above) did not show a sporulation-associated change in their localisation patterns. The carboxypeptidases PBP5* and DacF, that regulate the degree of cross-linking of the spore PG (Popham et al., 1999; Popham et al., 1995), have not been characterised in terms of their localisation.

\section{Life without a wall - conundrums and open questions.}

As we have seen, the shape of a Bacillus cell is tightly regulated and the cell wall is normally considered to be a semi-rigid structure. A striking example of adaptation of bacterial growth and division in the absence of a cell wall was given by Leaver et al. who were able to reproducible produce L-forms (Leaver et al., 2009). L-forms are bacteria that do not have a cell wall. L-forms are generated by prolonged growth of bacteria under conditions were PG synthesis is blocked however resulting L-forms are very often unstable and whether or not they were completely devoid of PG has been a matter of discussion (Allan, 1991; JoseleauPetit et al., 2007). Leaver et al. isolated stable L-forms by growing a strain in which the murE operon was shut down on a osmotically protected, high $\mathrm{Mg}^{+2}$ medium that contained high concentrations of penicillin. Interestingly, the stable Lforms obtained contained a point mutation in the active site of ispA, a protein involved in the isoprenoid synthesis pathway which leads to the formation of several essential lipids including bactoprenol that is required for Lipidll and TA precursor synthesis (Leaver et al., 2009). Next to ispA, mutations in walR or sepF also facilitate the transition from rod to L-forms (Dominguez-Cuevas et al., 2012). L-forms are spherical and have a much larger diameter than normal rod-shaped cells and propagate without FtsZ (Leaver et al., 2009). Division of L-forms is dependent on membrane composition and fluidity, as L-forms deficient in branched-chain membrane synthesis are not able to perform scission and separate (Mercier et al., 2012). Overproduction of fatty acids which generates an excess of membrane facilitates L-form division by increasing the cell surface to volume ratio, leading to cell shape deformation and division of the cell (Mercier et al., 2013). A similar proliferation mechanism, based on simple biophysical principles, has been reported in L-forms of $S$. aureus and $E$. coli, suggesting that this proliferation mechanism could also have been used by primitive cells (Mercier et al., 2014). As expected, B. subtilis L-forms are resistant to antibiotics that inhibit the bactoprenol cycle or peptidoglycan synthesis, but hypersensitive to antibiotics that impact on membrane stability (Tol et al., 2015; Wolf et al., 2012).

\section{Concluding remarks}

The study of cell wall synthesis has received a tremendous boost in the last few years because of the development of fluorescent and clickable D-amino acid analogues that reveal where PG synthesis takes place, improved microscopy techniques, and the determination of several structures of key proteins that play a role in peptidoglycan synthesis and cell shape determination. B. subtilis has been at the forefront of these developments, and will probably continue to be since it is one of the most extensively characterised bacteria in terms of mutant studies, the 
availability of localisation data, and the ease with which new reporter strains and deletions can be generated. Key future questions include the (local) architecture of the cell wall, the exact way $P G$ synthesis is regulated and the interplay between SEDS/PBP complexes and PBPs that function outside of these complexes, and the way the membrane, the environment at which PG synthesis takes place, influences the synthesis of peptidoglycan.

\section{Acknowledgements}

We would like to thank Valério Matias, Richard Daniel, Simon Foster, David Popham, Morgan Beeby and the late Terry Beveridge for the supply of, or the permission to adapt, figures.

\section{References}

Aaron, M., Charbon, G., Lam, H., Schwarz, H., Vollmer, W., and Jacobs-Wagner, C. (2007). The tubulin homologue FtsZ contributes to cell elongation by guiding cell wall precursor synthesis in Caulobacter crescentus. Mol. Microbiol. 64, 938-952.

Abanes-De Mello, A., Sun, Y.L., Aung, S., and Pogliano, K. (2002). A cytoskeleton-like role for the bacterial cell wall during engulfment of the Bacillus subtilis forespore. Genes and Development 16, 3253-3264.

Abhayawardhane, Y., and Stewart, G.C. (1995). Bacillus subtilis possesses a second determinant with extensive sequence similarity to the Escherichia coli mreB morphogene. J. Bacteriol. 177, 765-773.

Adams, D.W., and Errington, J. (2009). Bacterial cell division: assembly, maintenance and disassembly of the $Z$ ring. Nat Rev Microbiol 7, 642-653.

Allan, E.J. (1991). Induction and cultivation of a stable L-form of Bacillus subtilis. J. Appl. Bacteriol. 70, 339-343.

Alyahya, S.A., Alexander, R., Costa, T., Henriques, A.O., Emonet, T., and JacobsWagner, C. (2009). RodZ, a component of the bacterial core morphogenic apparatus. Proc. Natl. Acad. Sci. USA 106, 1239-1244.

Andre, G., Kulakauskas, S., Chapot-Chartier, M.P., Navet, B., Deghorain, M., Bernard, E., Hols, P., and Dufrene, Y.F. (2010). Imaging the nanoscale organization of peptidoglycan in living Lactococcus lactis cells. Nature Communications 1, 1-8.

Antelmann, H., Yamamoto, H., Sekiguchi, J., and Hecker, M. (2002). Stabilization of cell wall proteins in Bacillus subtilis: a proteomic approach. Proteomics 2, 591-602.

Ashiuchi, M., Soda, K., and Misono, H. (1999). Characterization of yrpC gene product of Bacillus subtilis IFO 3336 as glutamate racemase isozyme. Biosci Biotechnol Biochem 63, 792-798.

Atrih, A., Bacher, G., Allmaier, G., Williamson, M.P., and Foster, S.J. (1999). Analysis of peptidoglycan structure from vegetative cells of Bacillus subtilis 168 and role of PBP 5 in peptidoglycan maturation. J. Bacteriol. 181, 3956-3966.

Atrih, A., Zollner, P., Allmaier, G., and Foster, S.J. (1996). Structural analysis of Bacillus subtilis 168 endospore peptidoglycan and its role during differentiation. J. Bacteriol. 178, 6173-6183.

Bach, J.N., and Bramkamp, M. (2013). Flotillins functionally organize the bacterial membrane. Mol Microbiol 88, 1205-1217. 
Balomenou, S., Fouet, A., Tzanodaskalaki, M., Couture-Tosi, E., Bouriotis, V., and Boneca, I.G. (2013). Distinct functions of polysaccharide deacetylases in cell shape, neutral polysaccharide synthesis and virulence of Bacillus anthracis. Mol Microbiol 87, 867-883.

Barreteau, H., Kovac, A., Boniface, A., Sova, M., Gobec, S., and Blanot, D. (2008). Cytoplasmic steps of peptidoglycan biosynthesis. FEMS Microbiology Reviews 32, 168-207.

Beeby, M., Gumbart, J.C., Roux, B., and Jensen, G.J. (2013). Architecture and assembly of the Gram-positive cell wall. Mol Microbiol 88, 664-672.

Ben-Yehuda, S., and Losick, R. (2002). Asymmetric cell division in B. subtilis involves a spiral-like intermediate of the cytokinetic protein FtsZ. Cell 109, 257-266.

Bendezu, F.O., Hale, C.A., Bernhardt, T.G., and de Boer, P.A. (2009). RodZ (YfgA) is required for proper assembly of the MreB actin cytoskeleton and cell shape in E. coli. EMBO Journal 28, 193-204.

Bernardo-Garcia, N., Mahasenan, K.V., Batuecas, M.T., Lee, M., Hesek, D., Petrackova, D., Doubravova, L., Branny, P., Mobashery, S., and Hermoso, J.A. (2018). Allostery, Recognition of Nascent Peptidoglycan, and Cross-linking of the Cell Wall by the Essential Penicillin-Binding Protein 2x of Streptococcus pneumoniae. ACS Chem Biol 13, 694-702.

Bertsche, U., Breukink, E., Kast, T., and Vollmer, W. (2005). In vitro murein peptidoglycan synthesis by dimers of the bifunctional transglycosylasetranspeptidase PBP1B from Escherichia coli. J. Biol. Chem. 280, 38096-38101.

Bhavsar, A.P., and Brown, E.D. (2006). Cell wall assembly in Bacillus subtilis: how spirals and spaces challenge paradigms. Mol. Microbiol. 60, 1077-1090.

Bhavsar, A.P., Erdman, L.K., Schertzer, J.W., and Brown, E.D. (2004). Teichoic acid is an essential polymer in Bacillus subtilis that is functionally distinct from teichuronic acid. J. Bacteriol. 186, 7865-7873.

Billaudeau, C., Chastanet, A., Yao, Z., Cornilleau, C., Mirouze, N., Fromion, V., and Carballido-López, R. (2017). Contrasting mechanisms of growth in two model rod-shaped bacteria. Nature Communications 8.

Bisicchia, P., Noone, D., Lioliou, E., Howell, A., Quigley, S., Jensen, T., Jarmer, H., and Devine, K.M. (2007). The essential YycFG two-component system controls cell wall metabolism in Bacillus subtilis. Mol Microbiol 65, 180-200.

Bisson-Filho, A.W., Hsu, Y.-P., Squyres, G.R., Kuru, E., Wu, F., Jukes, C., Sun, Y., Dekker, C., Holden, S., VanNieuwenhze, M.S., et al. (2017). Treadmilling by FtsZ filaments drives peptidoglycan synthesis and bacterial cell division. Science (New York, NY) 355, 739-743.

Blackman, S.A., Smith, T.J., and Foster, S.J. (1998). The role of autolysins during vegetative growth of Bacillus subtilis 168. Microbiology 144, 73-82.

Bolla, J.R., Sauer, J.B., Wu, D., Mehmood, S., Allison, T.M., and Robinson, C.V. (2018). Direct observation of the influence of cardiolipin and antibiotics on lipid II binding to MurJ. Nat Chem 10, 363-371.

Boneca, I.G., Huang, Z.H., Gage, D.A., and Tomasz, A. (2000). Characterization of Staphylococcus aureus cell wall glycan strands, evidence for a new beta-Nacetylglucosaminidase activity. J. Biol. Chem. 275, 9910-9918. 
Bouhss, A., Trunkfield, A.E., Bugg, T.D.H., and Mengin-Lecreulx, D. (2008). The biosynthesis of peptidoglycan lipid-linked intermediates. FEMS Microbiology Reviews 32, 208-233.

Boyle, D.S., Khattar, M.M., Addinall, S.G., Lutkenhaus, J., and Donachie, W.D. (1997). ftsW is an essential cell-division gene in Escherichia coli. Mol. Microbiol. 24, 1263-1273.

Brown, S., Jr., J.P.S.M., and Walker, S. (2013). Wall Teichoic Acids of GramPositive Bacteria. Annual Review of Microbiology 67, 313-336.

Buchanan, C.E., and Ling, M.L. (1992). Isolation and sequence analysis of dacB, which encodes a sporulation-specific penicillin-binding protein in Bacillus subtilis. J. Bacteriol. 174, 1717-1725.

Bukowska-Faniband, E., and Hederstedt, L. (2013). Cortex synthesis during Bacillus subtilis sporulation depends on the transpeptidase activity of SpoVD. FEMS Microbiol Lett 346, 65-72.

Burman, L.G., Raichler, J., and Park, J.T. (1983). Evidence for diffuse growth of the cylindrical portion of the Escherichia coli murein sacculus. J. Bacteriol. 155, 983-988.

Burrows, L.L., and Lam, J.S. (1999). Effect of wzX (rfbX) mutations on A-band and B-band lipopolysaccharide biosynthesis in Pseudomonas aeruginosa $05 . \mathrm{J}$ Bacteriol 181, 973-980.

Calamita, H.G., Ehringer, W.D., Koch, A.L., and Doyle, R.J. (2001). Evidence that the cell wall of Bacillus subtilis is protonated during respiration. Proc. Natl. Acad. Sci. USA 98, 15260-15263.

Calvez, P., Jouhet, J., Vie, V., Durmort, C., and Zapun, A. (2019). Lipid Phases and Cell Geometry During the Cell Cycle of Streptococcus pneumoniae. Frontiers in microbiology 10, 351.

Carballido-López, R. (2006). The Bacterial Actin-Like Cytoskeleton. Microbiol Mol Biol Rev 70, 888-909.

Carballido-López, R., and Errington, J. (2003). The Bacterial Cytoskeleton. In Vivo Dynamics of the Actin-like Protein Mbl of Bacillus subtilis. Developmental Cell 4, 19-28.

Carballido-López, R., Formstone, A., Li, Y., Ehrlich, S.D., Noirot, P., and Errington, J. (2006). Actin homolog MreBH governs cell morphogenesis by localization of the cell wall hydrolase LytE. Dev Cell 11, 399-409.

Cava, F., de Pedro, M.A., Lam, H., Davis, B.M., and Waldor, M.K. (2011). Distinct pathways for modification of the bacterial cell wall by non-canonical D-amino acids. EMBO J 30, 3442-3453.

Chastanet, A., and Losick, R. (2007). Engulfment during sporulation in Bacillus subtilis is governed by a multi-protein complex containing tandemly acting autolysins. Mol. Microbiol. 64, 139-152.

Chen, Y., Zhang, W., Shi, Q., Hesek, D., Lee, M., Mobashery, S., and Shoichet, B.K. (2009). Crystal structures of penicillin-binding protein 6 from Escherichia coli. J. Amer. Chem. Soc. 131, 14345-14354.

Chirakkal, H., O'Rourke, M., Atrih, A., Foster, S.J., and Moir, A. (2002). Analysis of spore cortex lytic enzymes and related proteins in Bacillus subtilis endospore germination. Microbiology 148, 2383-2392.

Cho, H., Wivagg, C.N., Kapoor, M., Barry, Z., Rohs, P.D.A., Suh, H., Marto, J.A., Garner, E.C., and Bernhardt, T.G. (2016). Bacterial cell wall biogenesis is 
mediated by SEDS and PBP polymerase families functioning semiautonomously. Nat Microbiol 1, 16172.

Claessen, D., Emmins, R., Hamoen, L.W., Daniel, R.A., Errington, J., and Edwards, D.H. (2008). Control of the cell elongation-division cycle by shuttling of PBP1 protein in Bacillus subtilis. Mol. Microbiol. 68, 1029-1046.

Clarke-Sturman, A.J., Archibald, A.R., Hancock, I.C., Harwood, C.R., Merad, T., and Hobot, J.A. (1989). Cell wall assembly in Bacillus subtilis: partial conservation of polar wall material and the effect of growth conditions on the pattern of incorporation of new material at the polar caps. J Gen Microbiol 135, 657-665.

Cleverley, R.M., Rismondo, J., Lockhart-Cairns, M.P., Van Bentum, P.T., Egan, A.J., Vollmer, W., Halbedel, S., Baldock, C., Breukink, E., and Lewis, R.J. (2016). Subunit Arrangement in GpsB, a Regulator of Cell Wall Biosynthesis. Microb Drug Resist.

Cooper, S., and Hsieh, M.L. (1988). The rate and topography of cell wall synthesis during the division cycle of Escherichia coli using $\mathrm{N}$-acetylglucosamine as a peptidoglycan label. J. Gen. Microbiol. 134, 1717-1721.

D'Elia, M.A., Millar, K.E., Beveridge, T.J., and Brown, E.D. (2006a). Wall teichoic acid polymers are dispensable for cell viability in Bacillus subtilis. J. Bacteriol. 188, 8313-8316.

D'Elia, M.A., Pereira, M.P., Chung, Y.S., Zhao, W., Chau, A., Kenney, T.J., Sulavik, M.C., Black, T.A., and Brown, E.D. (2006b). Lesions in teichoic acid biosynthesis in Staphylococcus aureus lead to a lethal gain of function in the otherwise dispensable pathway. J. Bacteriol. 188, 4183-4189.

Dajkovic, A., Tesson, B., Chauhan, S., Courtin, P., Keary, R., Flores, P., Marliere, C., Filipe, S.R., Chapot-Chartier, M.P., and Carballido-Lopez, R. (2017). Hydrolysis of peptidoglycan is modulated by amidation of meso-diaminopimelic acid and $\mathrm{Mg}(2+)$ in Bacillus subtilis. Mol Microbiol 104, 972-988.

Daniel, R.A., Drake, S., Buchanan, C.E., Scholle, R., and Errington, J. (1994a). The Bacillus subtilis spoVD gene encodes a mother-cell-specific penicillinbinding protein required for spore morphogenesis. J Mol Biol 235, 209-220.

Daniel, R.A., Drake, S., Buchanan, C.E., Scholle, R., and Errington, J. (1994b). The Bacillus subtilis spoVD gene encodes a mother-cell-specific penicillinbinding protein required for spore morphogenesis. J. Mol. Biol. 235, 209-220.

Daniel, R.A., and Errington, J. (2003). Control of cell morphogenesis in bacteria: two distinct ways to make a rod-shaped cell. Cell 113, 767-776.

Daniel, R.A., Harry, E.J., and Errington, J. (2000). Role of penicillin-binding protein PBP 2B in assembly and functioning of the division machinery of Bacillus subtilis. Mol Microbiol 35, 299-311.

Daniel, R.A., Noirot-Gros, M.F., Noirot, P., and Errington, J. (2006). Multiple interactions between the transmembrane division proteins of Bacillus subtilis and the role of FtsL instability in divisome assembly. J Bacteriol 188, 7396-7404.

de Pedro, M.A., Donachie, W.D., Höltje, J.V., and Schwarz, H. (2001). Constitutive septal murein synthesis in Escherichia coli with impaired activity of the morphogenetic proteins RodA and penicillin-binding protein 2. J. Bacteriol. $183,4115-4126$. 
de Pedro, M.A., Grunfelder, C.G., and Schwarz, H. (2004). Restricted Mobility of Cell Surface Proteins in the Polar Regions of Escherichia coli. J. Bacteriol. 186, 2594-2602.

de Pedro, M.A., Quintela, J.C., Höltje, J.V., and Schwarz, H. (1997). Murein segregation in Escherichia coli. J. Bacteriol. 179, 2823-2834.

de Pedro, M.A., Young, K.D., Holtje, J.V., and Schwarz, H. (2003). Branching of Escherichia coli cells arises from multiple sites of inert peptidoglycan. J Bacteriol 185, 1147-1152.

Defeu Soufo, H.J., and Graumann, P.L. (2003). Actin-like proteins MreB and Mbl from Bacillus subtilis are required for bipolar positioning of replication origins. Current Biology 13, 1916-1920.

Defeu Soufo, H.J., and Graumann, P.L. (2004). Dynamic movement of actin-like proteins within bacterial cells. EMBO Reports 5, 789-794.

Defeu Soufo, H.J., and Graumann, P.L. (2006). Dynamic localization and interaction with other Bacillus subtilis actin-like proteins are important for the function of MreB. Mol. Microbiol. 62, 1340-1356.

Defeu Soufo, H.J., and Graumann, P.L. (2010). Bacillus subtilis MreB paralogues have different filament architectures and lead to shape remodelling of a heterologous cell system. Mol. Microbiol. 78, 1145-1158.

Dion, M.F., Kapoor, M., Sun, Y., Wilson, S., Ryan, J., Vigouroux, A., van Teeffelen, S., Oldenbourg, R., and Garner, E.C. (2019). Bacillus subtilis cell diameter is determined by the opposing actions of two distinct cell wall synthetic systems. Nat Microbiol.

Divakaruni, A.V., Loo, R.R., Xie, Y., Loo, J.A., and Gober, J.W. (2005). The cellshape protein MreC interacts with extracytoplasmic proteins including cell wall assembly complexes in Caulobacter crescentus. Proc. Natl. Acad. Sci. USA 102, 18602-18607.

Diven, W.F., Scholz, J.J., and Johnston, R.B. (1964). Purification and Properties of the Alanine Racemase from Bacillus Subtilis. Biochimica et Biophysica Acta 85, 322-332.

Dmitriev, B., Toukach, F., and Ehlers, S. (2005). Towards a comprehensive view of the bacterial cell wall. Trends in Microbiology 13, 569-574.

Dobihal, G.S., Brunet, Y.R., Flores-Kim, J., and Rudner, D.Z. (2019). Homeostatic control of cell wall hydrolysis by the WalRK two-component signaling pathway in Bacillus subtilis. eLife 8.

Dominguez-Cuevas, P., Mercier, R., Leaver, M., Kawai, Y., and Errington, J. (2012). The rod to L-form transition of Bacillus subtilis is limited by a requirement for the protoplast to escape from the cell wall sacculus. Mol Microbiol 83, 52-66.

Dominguez-Cuevas, P., Porcelli, I., Daniel, R.A., and Errington, J. (2013). Differentiated roles for MreB-actin isologues and autolytic enzymes in Bacillus subtilis morphogenesis. Mol Microbiol 89, 1084-1098.

Dominguez-Escobar, J., Chastanet, A., Crevenna, A.H., Fromion, V., WedlichSoldner, R., and Carballido-Lopez, R. (2011). Processive movement of MreBassociated cell wall biosynthetic complexes in bacteria. Science 333, 225-228.

Ehlert, K., and Holtje, J.V. (1996). Role of precursor translocation in coordination of murein and phospholipid synthesis in Escherichia coli. J. Bacteriol. 178, 6766-6771. 
Eichenberger, P., Jensen, S.T., Conlon, E.M., van Ooij, C., Silvaggi, J., GonzalezPastor, J.E., Fujita, M., Ben-Yehuda, S., Stragier, P., Liu, J.S., et al. (2003). The $\mathrm{sE}$ regulon and the identification of additional sporulation genes in Bacillus subtilis. J. Mol. Biol. 327, 945-972.

El Zoeiby, A., Sanschagrin, F., and Levesque, R.C. (2003). Structure and function of the Mur enzymes: development of novel inhibitors. Mol. Microbiol. 47, 1-12.

Emami, K., Guyet, A., Kawai, Y., Devi, J., Wu, L.J., Allenby, N., Daniel, R.A., and Errington, J. (2017). RodA as the missing glycosyltransferase in Bacillus subtilis and antibiotic discovery for the peptidoglycan polymerase pathway. Nat Microbiol 2, 16253.

Errington, J., Daniel, R.A., and Scheffers, D.J. (2003). Cytokinesis in bacteria. Microbiol Mol Biol Rev 67, 52-65.

Fay, A., and Dworkin, J. (2009). Bacillus subtilis homologs of MviN (MurJ), the putative Escherichia coli lipid II flippase, are not essential for growth. J. Bacteriol. 191, 6020-6028.

Fay, A., Meyer, P., and Dworkin, J. (2010). Interactions between late-acting proteins required for peptidoglycan synthesis during sporulation. J. Mol. Biol. 399, 547-561.

Ferrari, E., Henner, D.J., and Yang, M.Y. (1985). Isolation of an alanine racemase gene from Bacillus subtilis and its use for plasmid maintenance in $B$. subtilis. Biotechnology (NY) 3, 1003-1007.

Figge, R.M., Divakaruni, A.V., and Gober, J.W. (2004). MreB, the cell shapedetermining bacterial actin homologue, co-ordinates cell wall morphogenesis in Caulobacter crescentus. Mol. Microbiol. 51, 1321-1332.

Foley, M., Brass, J.M., Birmingham, J., Cook, W.R., Garland, P.B., Higgins, C.F., and Rothfield, L.I. (1989). Compartmentalization of the periplasm at cell division sites in Escherichia coli as shown by fluorescence photobleaching experiments. Mol. Microbiol. 3, 1329-1336.

Formstone, A., Carballido-Lopez, R., Noirot, P., Errington, J., and Scheffers, D.J. (2008). Localization and interactions of teichoic acid synthetic enzymes in Bacillus subtilis. J. Bacteriol. 190, 1812-1821.

Formstone, A., and Errington, J. (2005). A magnesium-dependent mreB null mutant: implications for the role of mreB in Bacillus subtilis. Mol. Microbiol. 55, 1646-1657.

Foster, S.J., and Popham, D.L. (2002). Structure and synthesis of cell wall, spore cortex, teichoic acids, S-layers, and capsules. In Bacillus subtilis and its closest relatives: from genes to cells, L. Sonenshein, R. Losick, and J.A. Hoch, eds. (Washington, D.C.: American Society for Microbiology), pp. 21-41.

Fotheringham, I.G., Bledig, S.A., and Taylor, P.P. (1998). Characterization of the genes encoding $D$-amino acid transaminase and glutamate racemase, two $D$ glutamate biosynthetic enzymes of Bacillus sphaericus ATCC 10208. J. Bacteriol. 180, 4319-4323.

Foulquier, E., Pompeo, F., Freton, C., Cordier, B., Grangeasse, C., and Galinier, A. (2014). PrkC-mediated phosphorylation of overexpressed YvcK protein regulates PBP1 protein localization in Bacillus subtilis mreB mutant cells. J Biol Chem 289, 23662-23669.

Fraipont, C., Sapunaric, F., Zervosen, A., Auger, G., Devreese, B., Lioux, T., Blanot, D., Mengin-Lecreulx, D., Herdewijn, P., Van Beeumen, J., et al. (2006). 
Glycosyl transferase activity of the Escherichia coli penicillin-binding protein $1 \mathrm{~b}$ : specificity profile for the substrate. Biochemistry 45, 4007-4013.

Fukushima, T., Yamamoto, H., Atrih, A., Foster, S.J., and Sekiguchi, J. (2002). A polysaccharide deacetylase gene (pdaA) is required for germination and for production of muramic delta-lactam residues in the spore cortex of Bacillus subtilis. J. Bacteriol. 184, 6007-6015.

Fura, J.M., Kearns, D., and Pires, M.M. (2015). D-Amino Acid Probes for Penicillin Binding Protein-based Bacterial Surface Labeling. J Biol Chem 290, 30540-30550.

Gan, L., Chen, S., and Jensen, G.J. (2008). Molecular organization of Gramnegative peptidoglycan. Proc. Natl. Acad. Sci. USA 105, 18953-18957.

Garner, E.C., Bernard, R., Wang, W., Zhuang, X., Rudner, D.Z., and Mitchison, T. (2011). Coupled, circumferential motions of the cell wall synthesis machinery and MreB filaments in B. subtilis. Science 333, 222-225.

Ghuysen, J.M. (1991). Serine b-lactamases and penicillin-binding proteins. Annual Review of Microbiology 45, 37-67.

Gilmore, M.E., Bandyopadhyay, D., Dean, A.M., Linnstaedt, S.D., and Popham, D.L. (2004). Production of muramic delta-lactam in Bacillus subtilis spore peptidoglycan. J. Bacteriol. 186, 80-89.

Ginsberg, C., Zhang, Y.H., Yuan, Y., and Walker, S. (2006). In vitro reconstitution of two essential steps in wall teichoic acid biosynthesis. ACS Chemical Biology 1, 25-28.

Gitai, Z., Dye, N., and Shapiro, L. (2004). An actin-like gene can determine cell polarity in bacteria. Proc. Natl. Acad. Sci. USA 101, 8643-8648.

Gitai, Z., Dye, N.A., Reisenauer, A., Wachi, M., and Shapiro, L. (2005). MreB actin-mediated segregation of a specific region of a bacterial chromosome. Cell 120, 329-341.

Goffin, C., Fraipont, C., Ayala, J., Terrak, M., Nguyen-Distèche, M., and Ghuysen, J.M. (1996). The non-penicillin-binding module of the tripartite penicillin-binding protein 3 of Escherichia coli is required for folding and/or stability of the penicillin-binding module and the membrane-anchoring module confers cell septation activity on the folded structure. J. Bacteriol. 178, 5402-5409.

Goffin, C., and Ghuysen, J.M. (1998). Multimodular penicillin-binding proteins: an enigmatic family of orthologs and paralogs. Microbiol Mol Biol Rev 62, 1079-1093.

Gorke, B., Foulquier, E., and Galinier, A. (2005). YvcK of Bacillus subtilis is required for a normal cell shape and for growth on Krebs cycle intermediates and substrates of the pentose phosphate pathway. Microbiology 151, 3777-3791.

Graham, L.L., and Beveridge, T.J. (1994). Structural differentiation of the Bacillus subtilis 168 cell wall. J. Bacteriol. 176, 1413-1421.

Grundling, A., and Schneewind, O. (2007a). Genes required for glycolipid synthesis and lipoteichoic acid anchoring in Staphylococcus aureus. J. Bacteriol. 189, 2521-2530.

Grundling, A., and Schneewind, O. (2007b). Synthesis of glycerol phosphate lipoteichoic acid in Staphylococcus aureus. Proc. Natl. Acad. Sci. USA 104, 8478-8483. 
Gullbrand, B., Akerlund, T., and Nordstrom, K. (1999). On the origin of branches in Escherichia coli. J. Bacteriol. 181, 6607-6614.

Hashimoto, M., Ooiwa, S., and Sekiguchi, J. (2012). Synthetic lethality of the lytE cwlO genotype in Bacillus subtilis is caused by lack of D,L-endopeptidase activity at the lateral cell wall. J Bacteriol 194, 796-803.

Hayhurst, E.J., Kailas, L., Hobbs, J.K., and Foster, S.J. (2008). Cell wall peptidoglycan architecture in Bacillus subtilis. Proc. Natl. Acad. Sci. USA 105, 14603-14608.

Heaslet, H., Shaw, B., Mistry, A., and Miller, A.A. (2009). Characterization of the active site of $S$. aureus monofunctional glycosyltransferase (Mtg) by sitedirected mutation and structural analysis of the protein complexed with moenomycin. Journal of Structural Biology 167, 129-135.

Helmann, J.D., and P, M.C., Jr. (2002). RNA polymerase and sigma factors. In Bacillus subtilis and Its Closest Relatives-From Genes to Cells, A.L. Sonenshein, J.A. Hoch, and R. Losick, eds. (Washington, DC: ASM Press), pp. 289-312.

Henriques, A.O., De Lencastre, H., and Piggot, P.J. (1992). A Bacillus subtilis morphogene cluster that includes spoVE is homologous to the mra region of Escherichia coli. Biochimie 74, 735-748.

Henriques, A.O., Glaser, P., Piggot, P.J., and P, M.C., Jr. (1998). Control of cell shape and elongation by the rodA gene in Bacillus subtilis. Mol. Microbiol. 28, 235-247.

Hoffmann, C., Leis, A., Niederweis, M., Plitzko, J.M., and Engelhardt, H. (2008). Disclosure of the mycobacterial outer membrane: cryo-electron tomography and vitreous sections reveal the lipid bilayer structure. Proc. Natl. Acad. Sci. USA 105, 3963-3967.

Höltje, J.V. (1996). A hypothetical holoenzyme involved in the replication of the murein sacculus of Escherichia coli. Microbiology 142, 1911-1918.

Höltje, J.V. (1998). Growth of the stress-bearing and shape-maintaining murein sacculus of Escherichia coli. Microbiology and Molecular Biology Reviews 62, 181-203.

Horsburgh, G.J., Atrih, A., and Foster, S.J. (2003a). Characterization of LytH, a differentiation-associated peptidoglycan hydrolase of Bacillus subtilis involved in endospore cortex maturation. J. Bacteriol. 185, 3813-3820.

Horsburgh, G.J., Atrih, A., Williamson, M.P., and Foster, S.J. (2003b). LytG of Bacillus subtilis is a novel peptidoglycan hydrolase: the major active glucosaminidase. Biochemistry 42, 257-264.

Huang, W.Z., Wang, J.J., Chen, H.J., Chen, J.T., and Shaw, G.C. (2013). The heat-inducible essential response regulator WaIR positively regulates transcription of sigl, $m r e B H$ and lytE in Bacillus subtilis under heat stress. Res Microbiol 164, 998-1008.

Hussain, S., Wivagg, C.N., Szwedziak, P., Wong, F., Schaefer, K., Izoré, T., Renner, L.D., Holmes, M.J., Sun, Y., Bisson-Filho, A.W., et al. (2018). MreB filaments align along greatest principal membrane curvature to orient cell wall synthesis. eLife 7, e32471.

Hvorup, R.N., Winnen, B., Chang, A.B., Jiang, Y., Zhou, X.F., and Saier, M.H., Jr. (2003). The multidrug/oligosaccharidyl-lipid/polysaccharide (MOP) exporter superfamily. Eur J Biochem 270, 799-813. 
Inoue, A., Murata, Y., Takahashi, H., Tsuji, N., Fujisaki, S., and Kato, J. (2008). Involvement of an essential gene, mviN, in murein synthesis in Escherichia coli. J. Bacteriol. 190, 7298-7301.

Ishikawa, S., Hara, Y., Ohnishi, R., and Sekiguchi, J. (1998). Regulation of a new cell wall hydrolase gene, cwlF, which affects cell separation in Bacillus subtilis. J. Bacteriol. 180, 2549-2555.

Ishino, F., and Matsuhashi, M. (1981). Peptidoglycan synthetic enzyme activities of highly purified penicillin-binding protein 3 in Escherichia coli: a septumforming reaction sequence. Biochemical and Biophysical Research Communications 101, 905-911.

Ishino, F., Park, W., Tomioka, S., Tamaki, S., Takase, I., Kunugita, K., Matsuzawa, H., Asoh, S., Ohta, T., Spratt, B.G., et al. (1986). Peptidoglycan synthetic activities in membranes of Escherichia coli caused by overproduction of penicillin-binding protein 2 and RodA protein. J. Biol. Chem. 261, 7024-7031.

Jeske, O., Schuler, M., Schumann, P., Schneider, A., Boedeker, C., Jogler, M., Bollschweiler, D., Rohde, M., Mayer, C., Engelhardt, H., et al. (2015). Planctomycetes do possess a peptidoglycan cell wall. Nat Commun 6, 7116.

Johnson, J.W., Fisher, J.F., and Mobashery, S. (2013). Bacterial cell-wall recycling. Annals of the New York Academy of Sciences 1277, 54-75.

Jolliffe, L.K., Doyle, R.J., and Streips, U.N. (1981). The energized membrane and cellular autolysis in Bacillus subtilis. Cell 25, 753-763.

Jolliffe, L.K., Langemeier, S.O., and Doyle, R.J. (1983). Hydrogen ion control of autolysin-dependent functions in Bacillus subtilis. Microbios 38, 187-194.

Jones, L.J.F., Carballido-López, R., and Errington, J. (2001). Control of cell shape in bacteria: helical, actin-like filaments in Bacillus subtilis. Cell 104, 913-922.

Jorasch, P., Wolter, F.P., Zahringer, U., and Heinz, E. (1998). A UDP glucosyltransferase from Bacillus subtilis successively transfers up to four glucose residues to 1,2-diacylglycerol: expression of ypfP in Escherichia coli and structural analysis of its reaction products. Mol. Microbiol. 29, 419-430.

Joseleau-Petit, D., Liebart, J.C., Ayala, J.A., and D'Ari, R. (2007). Unstable Escherichia coli $\mathrm{L}$ forms revisited: growth requires peptidoglycan synthesis. J. Bacteriol. 189, 6512-6520.

Kasahara, J., Kiriyama, Y., Miyashita, M., Kondo, T., Yamada, T., Yazawa, K., Yoshikawa, R., and Yamamoto, H. (2016). Teichoic Acid Polymers Affect Expression and Localization of dl-Endopeptidase LytE Required for Lateral Cell Wall Hydrolysis in Bacillus subtilis. J Bacteriol 198, 1585-1594.

Kawai, Y., Asai, K., and Errington, J. (2009a). Partial functional redundancy of MreB isoforms, MreB, $\mathrm{Mbl}$ and $\mathrm{MreBH}$, in cell morphogenesis of Bacillus subtilis. Mol. Microbiol. 73, 719-731.

Kawai, Y., Daniel, R.A., and Errington, J. (2009b). Regulation of cell wall morphogenesis in Bacillus subtilis by recruitment of PBP1 to the MreB helix. Mol. Microbiol. 71, 1131-1144.

Kemper, M.A., Urrutia, M.M., Beveridge, T.J., Koch, A.L., and Doyle, R.J. (1993). Proton motive force may regulate cell wall-associated enzymes of Bacillus subtilis. J. Bacteriol. 175, 5690-5696.

Kern, T., Giffard, M., Hediger, S., Amoroso, A., Giustini, C., Bui, N.K., Joris, B., Bougault, C., Vollmer, W., and Simorre, J.P. (2010). Dynamics characterization 
of fully hydrated bacterial cell walls by solid-state NMR: evidence for cooperative binding of metal ions. J. Amer. Chem. Soc. 132, 10911-10919.

Khanna, K., Lopez-Garrido, J., and Pogliano, K. (2020). Shaping an Endospore: Architectural Transformations During Bacillus subtilis Sporulation. Annual Review of Microbiology 74, null.

Khanna, K., Lopez-Garrido, J., Zhao, Z., Watanabe, R., Yuan, Y., Sugie, J., Pogliano, K., and Villa, E. (2019). The molecular architecture of engulfment during Bacillus subtilis sporulation. eLife 8, e45257.

Kim, S.Y., Gitai, Z., Kinkhabwala, A., Shapiro, L., and Moerner, W.E. (2006). Single molecules of the bacterial actin MreB undergo directed treadmilling motion in Caulobacter crescentus. Proc. Natl. Acad. Sci. USA 103, 10929-10934.

Kiriyama, Y., Yazawa, K., Tanaka, T., Yoshikawa, R., Yamane, H., Hashimoto, M., Sekiguchi, J., and Yamamoto, H. (2014). Localization and expression of the Bacillus subtilis DL-endopeptidase LytF are influenced by mutations in LTA synthases and glycolipid anchor synthetic enzymes. Microbiology 160, 2639-2649.

Knowles, T.J., Finka, R., Smith, C., Lin, Y.P., Dafforn, T., and Overduin, M. (2009). Membrane proteins solubilized intact in lipid containing nanoparticles bounded by styrene maleic acid copolymer. J Am Chem Soc 131, 7484-7485.

Koch, A.L. (2000). The bacterium's way for safe enlargement and division. Applied and Environmental Microbiology 66, 3657-3663.

Koch, A.L., and Doyle, R.J. (1985). Inside-to-outside growth and turnover of the wall of gram-positive rods. Journal of Theoretical Biology 117, 137-157.

Korat, B., Mottl, H., and Keck, W. (1991). Penicillin-binding protein 4 of Escherichia coli: molecular cloning of the dacB gene, controlled overexpression, and alterations in murein composition. Mol. Microbiol. 5, 675-684.

Koskiniemi, S., Lamoureux, J.G., Nikolakakis, K.C., t'Kint de Roodenbeke, C., Kaplan, M.D., Low, D.A., and Hayes, C.S. (2013). Rhs proteins from diverse bacteria mediate intercellular competition. Proc. Natl. Acad. Sci. USA 110, 7032-7037.

Kruse, T., Bork-Jensen, J., and Gerdes, K. (2005). The morphogenetic MreBCD proteins of Escherichia coli form an essential membrane-bound complex. Mol. Microbiol. 55, 78-89.

Kuk, A.C.Y., Hao, A., Guan, Z., and Lee, S.Y. (2019). Visualizing conformation transitions of the Lipid II flippase MurJ. Nat Commun 10.

Kuk, A.C.Y., Mashalidis, E.H., and Lee, S.Y. (2017). Crystal structure of the MOP flippase MurJ in an inward-facing conformation. Nat Struct Mol Biol 24, 171-176.

Kumar, S., Rubino, F.A., Mendoza, A.G., and Ruiz, N. (2019). The bacterial lipid II flippase MurJ functions by an alternating-access mechanism. J Biol Chem 294, 981-990.

Kuru, E., Hughes, H.V., Brown, P.J., Hall, E., Tekkam, S., Cava, F., de Pedro, M.A., Brun, Y.V., and VanNieuwenhze, M.S. (2012). In situ probing of newly synthesized peptidoglycan in live bacteria with fluorescent D-amino acids. Angew Chem Int Ed Engl 51, 12519-12523.

Kuru, E., Tekkam, S., Hall, E., Brun, Y.V., and Van Nieuwenhze, M.S. (2015). Synthesis of fluorescent D-amino acids and their use for probing peptidoglycan synthesis and bacterial growth in situ. Nat Protoc 10, 33-52. 
Lages, M.C., Beilharz, K., Morales Angeles, D., Veening, J.W., and Scheffers, D.J. (2013). The localization of key Bacillus subtilis penicillin binding proteins during cell growth is determined by substrate availability. Environ Microbiol 15, 3272-3281.

Lawrence, P.J., and Strominger, J.L. (1970). Biosynthesis of the peptidoglycan of bacterial cell walls. XVI. The reversible fixation of radioactive penicillin $\mathrm{G}$ to the D-alanine carboxypeptidase of Bacillus subtilis. J. Biol. Chem. 245, 3660-3666.

Lazarevic, V., and Karamata, D. (1995). The tagGH operon of Bacillus subtilis 168 encodes a two-component $A B C$ transporter involved in the metabolism of two wall teichoic acids. Mol. Microbiol. 16, 345-355.

Leaver, M., Dominguez-Cuevas, P., Coxhead, J.M., Daniel, R.A., and Errington, J. (2009). Life without a wall or division machine in Bacillus subtilis. Nature 457, 849-853.

Leaver, M., and Errington, J. (2005). Roles for MreC and MreD proteins in helical growth of the cylindrical cell wall in Bacillus subtilis. Mol. Microbiol. 57, 1196-1209.

Lee, J.C., and Stewart, G.C. (2003). Essential nature of the mreC determinant of Bacillus subtilis. J. Bacteriol. 185, 4490-4498.

Levin, P.A., Margolis, P.S., Setlow, P., Losick, R., and Sun, D. (1992). Identification of Bacillus subtilis genes for septum placement and shape determination. J. Bacteriol. 174, 6717-6728.

Li, K., Yuan, X.-X., Sun, H.-M., Zhao, L.-S., Tang, R., Chen, Z.-H., Qin, Q.-L., Chen, X.-L., Zhang, Y.-Z., and Su, H.-N. (2018). Atomic Force Microscopy of Side Wall and Septa Peptidoglycan From Bacillus subtilis Reveals an Architectural Remodeling During Growth. Frontiers in microbiology 9.

Liechti, G.W., Kuru, E., Hall, E., Kalinda, A., Brun, Y.V., VanNieuwenhze, M., and Maurelli, A.T. (2014). A new metabolic cell-wall labelling method reveals peptidoglycan in Chlamydia trachomatis. Nature 506, 507-510.

Litzinger, S., Duckworth, A., Nitzsche, K., Risinger, C., Wittmann, V., and Mayer, C. (2010). Muropeptide rescue in Bacillus subtilis involves sequential hydrolysis by beta- $\mathrm{N}$-acetylglucosaminidase and $\mathrm{N}$-acetylmuramyl-L-alanine amidase. J Bacteriol 192, 3132-3143.

Lovering, A.L., de Castro, L.H., Lim, D., and Strynadka, N.C. (2007). Structural insight into the transglycosylation step of bacterial cell-wall biosynthesis. Science 315, 1402-1405.

Macheboeuf, P., Di Guilmi, A.M., Job, V., Vernet, T., Dideberg, O., and Dessen, A. (2005). Active site restructuring regulates ligand recognition in class A penicillinbinding proteins. Proc. Natl. Acad. Sci. USA 102, 577-582.

Manat, G., Roure, S., Auger, R., Bouhss, A., Barreteau, H., Mengin-Lecreulx, D., and Touze, T. (2014). Deciphering the metabolism of undecaprenyl-phosphate: the bacterial cell-wall unit carrier at the membrane frontier. Microb Drug Resist 20, 199-214.

Manuse, S., Fleurie, A., Zucchini, L., Lesterlin, C., and Grangeasse, C. (2016). Role of eukaryotic-like serine/threonine kinases in bacterial cell division and morphogenesis. FEMS Microbiol Rev 40, 41-56.

Margolin, W. (2009). Sculpting the bacterial cell. Current Biology 19, R812-822. 
Margot, P., Mauel, C., and Karamata, D. (1994). The gene of the Nacetylglucosaminidase, a Bacillus subtilis 168 cell wall hydrolase not involved in vegetative cell autolysis. Mol. Microbiol. 12, 535-545.

Margot, P., Pagni, M., and Karamata, D. (1999). Bacillus subtilis 168 gene lytF encodes a g-D-glutamate-meso-diaminopimelate muropeptidase expressed by the alternative vegetative sigma factor, sD. Microbiology 145, 57-65.

Margot, P., Whalen, M., Gholamhoseinian, A., Piggot, P., and Karamata, D. (1998). The lytE gene of Bacillus subtilis 168 encodes a cell wall hydrolase. J. Bacteriol. 180, 749-752.

Markovski, M., Bohrhunter, J.L., Lupoli, T.J., Uehara, T., Walker, S., Kahne, D.E., and Bernhardt, T.G. (2016). Cofactor bypass variants reveal a conformational control mechanism governing cell wall polymerase activity. Proc Natl Acad Sci U S A 113, 4788-4793.

Massova, I., and Mobashery, S. (1998). Kinship and diversification of bacterial penicillin-binding proteins and beta-lactamases. Antimicrobial Agents and Chemotherapy 42, 1-17.

Matias, V.R., and Beveridge, T.J. (2005). Cryo-electron microscopy reveals native polymeric cell wall structure in Bacillus subtilis 168 and the existence of a periplasmic space. Mol. Microbiol. 56, 240-251.

Matias, V.R., and Beveridge, T.J. (2006). Native cell wall organization shown by cryo-electron microscopy confirms the existence of a periplasmic space in Staphylococcus aureus. J. Bacteriol. 188, 1011-1021.

Mattei, P.J., Neves, D., and Dessen, A. (2010). Bridging cell wall biosynthesis and bacterial morphogenesis. Current Opinion in Structural Biology 20, 749-755.

McPherson, D.C., Driks, A., and Popham, D.L. (2001). Two class A highmolecular-weight penicillin-binding proteins of Bacillus subtilis play redundant roles in sporulation. J. Bacteriol. 183, 6046-6053.

McPherson, D.C., and Popham, D.L. (2003). Peptidoglycan synthesis in the absence of Class A penicillin-binding proteins in Bacillus subtilis. J. Bacteriol. $185,1423-1431$.

Meeske, A.J., Riley, E.P., Robins, W.P., Uehara, T., Mekalanos, J.J., Kahne, D., Walker, S., Kruse, A.C., Bernhardt, T.G., and Rudner, D.Z. (2016). SEDS proteins are a widespread family of bacterial cell wall polymerases. Nature 537 , 634-638.

Meeske, A.J., Sham, L.T., Kimsey, H., Koo, B.M., Gross, C.A., Bernhardt, T.G., and Rudner, D.Z. (2015). MurJ and a novel lipid II flippase are required for cell wall biogenesis in Bacillus subtilis. Proc Natl Acad Sci U S A.

Meier, E.L., and Goley, E.D. (2014). Form and function of the bacterial cytokinetic ring. Current Opinion in Cell Biology 26, 19-27.

Meisner, J., Montero Llopis, P., Sham, L.T., Garner, E., Bernhardt, T.G., and Rudner, D.Z. (2013). FtsEX is required for CwlO peptidoglycan hydrolase activity during cell wall elongation in Bacillus subtilis. Mol Microbiol 89, 1069-1083.

Merchante, R., Pooley, H.M., and Karamata, D. (1995). A periplasm in Bacillus subtilis. J. Bacteriol. 177, 6176-6183.

Mercier, R., Dominguez-Cuevas, P., and Errington, J. (2012). Crucial role for membrane fluidity in proliferation of primitive cells. Cell Rep 1, 417-423. 
Mercier, R., Kawai, Y., and Errington, J. (2013). Excess membrane synthesis drives a primitive mode of cell proliferation. Cell 152, 997-1007.

Mercier, R., Kawai, Y., and Errington, J. (2014). General principles for the formation and proliferation of a wall-free (L-form) state in bacteria. eLife 3.

Meroueh, S.O., Bencze, K.Z., Hesek, D., Lee, M., Fisher, J.F., Stemmler, T.L., and Mobashery, S. (2006). Three-dimensional structure of the bacterial cell wall peptidoglycan. Proc. Natl. Acad. Sci. USA 103, 4404-4409.

Meyer, P., Gutierrez, J., Pogliano, K., and Dworkin, J. (2010). Cell wall synthesis is necessary for membrane dynamics during sporulation of Bacillus subtilis. Mol. Microbiol. 76, 956-970.

Mirouze, N., Ferret, C., Cornilleau, C., and Carballido-Lopez, R. (2018). Antibiotic sensitivity reveals that wall teichoic acids mediate DNA binding during competence in Bacillus subtilis. Nat Commun 9, 5072.

Miyachiro, M.M., Contreras-Martel, C., and Dessen, A. (2019). Penicillin-Binding Proteins (PBPs) and Bacterial Cell Wall Elongation Complexes. In Macromolecular Protein Complexes II: Structure and Function, J.R. Harris, and J. Marles-Wright, eds. (Cham: Springer International Publishing), pp. 273-289.

Mobley, H.L.T., Koch, A.L., Doyle, R.J., and Streips, U.N. (1984). Insertion and fate of the cell wall in Bacillus subtilis. J. Bacteriol. 158, 169-179.

Mohammadi, T., Karczmarek, A., Crouvoisier, M., Bouhss, A., Mengin-Lecreulx, D., and den Blaauwen, T. (2007). The essential peptidoglycan glycosyltransferase MurG forms a complex with proteins involved in lateral envelope growth as well as with proteins involved in cell division in Escherichia coli. Mol. Microbiol. 65, 1106-1121.

Mohammadi, T., Sijbrandi, R., Lutters, M., Verheul, J., Martin, N.I., den Blaauwen, T., de Kruijff, B., and Breukink, E. (2014). Specificity of the transport of lipid II by FtsW in Escherichia coli. J Biol Chem 289, 14707-14718.

Mohammadi, T., van Dam, V., Sijbrandi, R., Vernet, T., Zapun, A., Bouhss, A., Diepeveen-de Bruin, M., Nguyen-Disteche, M., de Kruijf, B., and Breukink, E. (2011). Identification of FtsW as a transporter of lipid-linked cell wall precursors across the membrane. EMBO J 30, 1425-1432.

Monteiro, J.M., Pereira, A.R., Reichmann, N.T., Saraiva, B.M., Fernandes, P.B., Veiga, H., Tavares, A.C., Santos, M., Ferreira, M.T., Macario, V., et al. (2018). Peptidoglycan synthesis drives an FtsZ-treadmilling-independent step of cytokinesis. Nature 554, 528-532.

Morales Angeles, D., Liu, Y., Hartman, A.M., Borisova, M., de SoUSA Borges, A., de Kok, N., Beilharz, K., Veening, J.-W., Mayer, C., Hirsch, A.K.H., et al. (2017a). Pentapeptide-rich peptidoglycan at the Bacillus subtilis cell-division site. Mol. Microbiol. 104, 319-333.

Morales Angeles, D., Macia-Valero, A., Bohorquez, L.C., and Scheffers, D.-J. (2019). The PASTA domains of Bacillus subtilis PBP2B stabilize the interaction of PBP2B with DivIB. Microbiology 166, 826-836.

Morlot, C., Uehara, T., Marquis, K.A., Bernhardt, T.G., and Rudner, D.Z. (2010). A highly coordinated cell wall degradation machine governs spore morphogenesis in Bacillus subtilis. Genes and Development 24, 411-422.

Muchova, K., Chromikova, Z., and Barak, I. (2013). Control of Bacillus subtilis cell shape by RodZ. Environmental microbiology 15, 3259-3271. 
Murray, T., Popham, D.L., and Setlow, P. (1996). Identification and characterization of $\mathrm{pbpC}$, the gene encoding Bacillus subtilis penicillin-binding protein 3. J. Bacteriol. 178, 6001-6005.

Murray, T., Popham, D.L., and Setlow, P. (1997). Identification and characterization of pbpA encoding Bacillus subtilis penicillin-binding protein $2 \mathrm{~A}$. J. Bacteriol. 179, 3021-3029.

Nemmara, V.V., Adediran, S.A., Dave, K., Duez, C., and Pratt, R.F. (2013). Dual Substrate Specificity of Bacillus subtilis PBP4a. Biochemistry 52, 2627-2637.

Neuhaus, F.C., and Baddiley, J. (2003). A continuum of anionic charge: structures and functions of $\mathrm{D}$-alanyl-teichoic acids in gram-positive bacteria. Microbiology and Molecular Biology Reviews 67, 686-723.

Noback, M.A., Holsappel, S., Kiewiet, R., Terpstra, P., Wambutt, R., Wedler, H., Venema, G., and Bron, S. (1998). The $172 \mathrm{~kb}$ prkA-addAB region from 83 degrees to 97 degrees of the Bacillus subtilis chromosome contains several dysfunctional genes, the glyB marker, many genes encoding transporter proteins, and the ubiquitous hit gene. Microbiology 144, 859-875.

Nocadello, S., Minasov, G., Shuvalova, L.S., Dubrovska, I., Sabini, E., and Anderson, W.F. (2016). Crystal structures of the SpolID lytic transglycosylases essential for bacterial sporulation. J. Biol. Chem..

Noone, D., Salzberg, L.I., Botella, E., Basell, K., Becher, D., Antelmann, H., and Devine, K.M. (2014). A highly unstable transcript makes CwlO D,Lendopeptidase expression responsive to growth conditions in Bacillus subtilis. J Bacteriol 196, 237-247.

Nugroho, F.A., Yamamoto, H., Kobayashi, Y., and Sekiguchi, J. (1999). Characterization of a new sigma-K-dependent peptidoglycan hydrolase gene that plays a role in Bacillus subtilis mother cell lysis. J. Bacteriol. 181, 6230-6237.

Ohnishi, R., Ishikawa, S., and Sekiguchi, J. (1999). Peptidoglycan hydrolase LytF plays a role in cell separation with CwIF during vegetative growth of Bacillus subtilis. J. Bacteriol. 181, 3178-3184.

Parès, S., Mouz, N., Petillot, Y., Hakenbeck, R., and Dideberg, O. (1996). X-ray structure of Streptococcus pneumoniae PBP2x, a primary penicillin target enzyme. Nature Structural Biology 3, 284-289.

Pasquina-Lemonche, L., Burns, J., Turner, R.D., Kumar, S., Tank, R., Mullin, N., Wilson, J.S., Chakrabarti, B., Bullough, P.A., Foster, S.J., et al. (2020). The architecture of the Gram-positive bacterial cell wall. Nature.

Pedersen, L.B., Angert, E.R., and Setlow, P. (1999). Septal localization of penicillin-binding protein 1 in Bacillus subtilis. J. Bacteriol. 181, 3201-3211.

Pedersen, L.B., Murray, T., Popham, D.L., and Setlow, P. (1998). Characterization of dacC, which encodes a new low-molecular-weight penicillin-binding protein in Bacillus subtilis. J. Bacteriol. 180, 4967-4973.

Pedersen, L.B., Ragkousi, K., Cammett, T.J., Melly, E., Sekowska, A., Schopick, E., Murray, T., and Setlow, P. (2000). Characterization of ywhE, which encodes a putative high-molecular-weight class A penicillin-binding protein in Bacillus subtilis. Gene 246, 187-196.

Pereira, M.P., Schertzer, J.W., D'Elia, M.A., Koteva, K.P., Hughes, D.W., Wright, G.D., and Brown, E.D. (2008). The wall teichoic acid polymerase TagF 
efficiently synthesizes poly(glycerol phosphate) on the TagB product lipid III. ChemBioChem 9, 1385-1390.

Pilhofer, M., Aistleitner, K., Biboy, J., Gray, J., Kuru, E., Hall, E., Brun, Y.V., VanNieuwenhze, M.S., Vollmer, W., Horn, M., et al. (2013). Discovery of chlamydial peptidoglycan reveals bacteria with murein sacculi but without FtsZ. Nat Commun 4, 2856.

Pollack, J.H., and Neuhaus, F.C. (1994). Changes in wall teichoic acid during the rod-sphere transition of Bacillus subtilis 168. J. Bacteriol. 176, 7252-7259.

Pompeo, F., Foulquier, E., Serrano, B., Grangeasse, C., and Galinier, A. (2015). Phosphorylation of the cell division protein GpsB regulates PrkC kinase activity through a negative feedback loop in Bacillus subtilis. Mol Microbiol 97, 139-150.

Pompeo, F., Rismondo, J., Gründling, A., and Galinier, A. (2018). Investigation of the phosphorylation of Bacillus subtilis LTA synthases by the serine/threonine kinase PrkC. Scientific Reports 8, 17344.

Pooley, H.M., Abellan, F.X., and Karamata, D. (1991). A conditional-lethal mutant of Bacillus subtilis 168 with a thermosensitive glycerol-3-phosphate cytidylyltransferase, an enzyme specific for the synthesis of the major wall teichoic acid. J. Gen. Microbiol. 137, 921-928.

Pooley, H.M., Abellan, F.X., and Karamata, D. (1992). CDP-glycerol:poly (glycerophosphate) glycerophosphotransferase, which is involved in the synthesis of the major wall teichoic acid in Bacillus subtilis 168, is encoded by tagF (rodC). J. Bacteriol. 174, 646-649.

Pooley, H.M., Schlaeppi, J.M., and Karamata, D. (1978). Localised insertion of new cell wall in Bacillus subtilis. Nature 274, 264-266.

Popham, D.L., and Bernhards, C.B. (2016). Spore Peptidoglycan. In The Bacterial Spore, A. Driks, and P. Eichenberger, eds., pp. 157-177.

Popham, D.L., Gilmore, M.E., and Setlow, P. (1999). Roles of low-molecularweight penicillin-binding proteins in Bacillus subtilis spore peptidoglycan synthesis and spore properties. J. Bacteriol. 181, 126-132.

Popham, D.L., Helin, J., Costello, C.E., and Setlow, P. (1996). Muramic lactam in peptidoglycan of Bacillus subtilis spores is required for spore outgrowth but not for spore dehydration or heat resistance. Proc. Natl. Acad. Sci. USA 93, $15405-15410$.

Popham, D.L., Illades-Aguiar, B., and Setlow, P. (1995). The Bacillus subtilis dacB gene, encoding penicillin-binding protein $5^{*}$, is part of a three-gene operon required for proper spore cortex synthesis and spore core dehydration. J. Bacteriol. 177, 4721-4729.

Popham, D.L., and Setlow, P. (1993a). Cloning, nucleotide sequence, and regulation of the Bacillus subtilis pbpE operon, which codes for penicillin-binding protein $4^{*}$ and an apparent amino acid racemase. J. Bacteriol. 175, 2917-2925.

Popham, D.L., and Setlow, P. (1993b). Cloning, nucleotide sequence, and regulation of the Bacillus subtilis pbpF gene, which codes for a putative class $A$ high-molecular-weight penicillin-binding protein. J. Bacteriol. 175, 4870-4876.

Popham, D.L., and Setlow, P. (1994). Cloning, nucleotide sequence, mutagenesis, and mapping of the Bacillus subtilis pbpD gene, which codes for penicillinbinding protein 4. J. Bacteriol. 176, 7197-7205. 
Popham, D.L., and Setlow, P. (1995). Cloning, nucleotide sequence, and mutagenesis of the Bacillus subtilis ponA operon, which codes for penicillinbinding protein (PBP) 1 and a PBP-related factor. J. Bacteriol. 177, 326-335.

Popham, D.L., and Setlow, P. (1996). Phenotypes of Bacillus subtilis mutants lacking multiple class a high-molecular-weight penicillin-binding proteins. J. Bacteriol. 178, 2079-2085.

Rahman, O., Dover, L.G., and Sutcliffe, I.C. (2009). Lipoteichoic acid biosynthesis: two steps forwards, one step sideways? Trends in Microbiology 17, 219-225.

Rashid, M.H., Mori, M., and Sekiguchi, J. (1995). Glucosaminidase of Bacillus subtilis: cloning, regulation, primary structure and biochemical characterization. Microbiology 141, 2391-2404.

Real, G., and Henriques, A.O. (2006). Localization of the Bacillus subtilis murB gene within the dcw cluster is important for growth and sporulation. J. Bacteriol. 188, 1721-1732.

Reith, J., and Mayer, C. (2011). Peptidoglycan turnover and recycling in Grampositive bacteria. Appl Microbiol Biotechnol 92, 1-11.

Rismondo, J., Cleverley, R.M., Lane, H.V., Grosshennig, S., Steglich, A., Moller, L., Mannala, G.K., Hain, T., Lewis, R.J., and Halbedel, S. (2016). Structure of the bacterial cell division determinant GpsB and its interaction with penicillinbinding proteins. Mol Microbiol 99, 978-998.

Robichon, C., King, G.F., Goehring, N.W., and Beckwith, J. (2008). Artificial septal targeting of Bacillus subtilis cell division proteins in Escherichia coli: an interspecies approach to the study of protein-protein interactions in multiprotein complexes. J. Bacteriol. 190, 6048-6059.

Rodrigues, C.D., Marquis, K.A., Meisner, J., and Rudner, D.Z. (2013). Peptidoglycan hydrolysis is required for assembly and activity of the transenvelope secretion complex during sporulation in Bacillus subtilis. Mol Microbiol 89, 1039-1052.

Rogers, H.J., Perkins, H.R., and Ward, J.B., Jr. (1980). Microbial cell walls and membranes (London: Chapman and Hall).

Romeis, T., and Holtje, J.V. (1994). Specific interaction of penicillin-binding proteins 3 and $7 / 8$ with soluble lytic transglycosylase in Escherichia coli. J. Biol. Chem. 269, 21603-21607.

Rowland, S.L., Wadsworth, K.D., Robson, S.A., Robichon, C., Beckwith, J., and King, G.F. (2010). Evidence from artificial septal targeting and site-directed mutagenesis that residues in the extracytoplasmic beta domain of DivIB mediate its interaction with the divisomal transpeptidase PBP 2B. J. Bacteriol. 192, 6116-6125.

Rowlett, V.W., and Margolin, W. (2015). The bacterial divisome: ready for its close-up. Philosophical Transactions of the Royal Society of London B: Biological Sciences 370.

Rubino, F.A., Kumar, S., Ruiz, N., Walker, S., and Kahne, D.E. (2018). Membrane Potential Is Required for MurJ Function. J Am Chem Soc 140, 4481-4484.

Ruiz, N. (2008). Bioinformatics identification of MurJ (MviN) as the peptidoglycan lipid II flippase in Escherichia coli. Proc. Natl. Acad. Sci. USA 105, 15553-15557. 
Ruiz, N. (2016). Lipid Flippases for Bacterial Peptidoglycan Biosynthesis. Lipid Insights, 21-31.

Salzberg, L.I., Powell, L., Hokamp, K., Botella, E., Noone, D., and Devine, K.M. (2013). The WalRK (YycFG) and sigma(I) Rsgl regulators cooperate to control CwIO and LytE expression in exponentially growing and stressed Bacillus subtilis cells. Mol Microbiol 87, 180-195.

Sarkar, S., Libby, E.A., Pidgeon, S.E., Dworkin, J., and Pires, M.M. (2016). In vivo Probe of Lipid II-Interacting Proteins. Angew Chem Int Ed Engl 55, 8401-8404.

Sassine, J., Xu, M., Sidiq, K.R., Emmins, R., Errington, J., and Daniel, R.A. (2017). Functional redundancy of division specific penicillin-binding proteins in Bacillus subtilis. Mol Microbiol 106, 304-318.

Sauvage, E., and Terrak, M. (2016). Glycosyltransferases and Transpeptidases/ Penicillin-Binding Proteins: Valuable Targets for New Antibacterials. Antibiotics 5, 12.

Scheffers, D.-J., Jones, L.J.F., and Errington, J. (2004). Several distinct localization patterns for penicillin-binding proteins in Bacillus subtilis. Mol Microbiol 51, 749-764.

Scheffers, D.-J., and Tol, M.B. (2015). Lipidll: Just Another Brick in the Wall? PLoS pathogens 11, e1005213.

Scheffers, D.J. (2005). Dynamic localization of penicillin-binding proteins during spore development in Bacillus subtilis. Microbiology 151, 999-1012.

Scheffers, D.J., and Pinho, M.G. (2005). Bacterial cell wall synthesis: new insights from localization studies. Microbiol Mol Biol Rev 69, 585-607.

Schirner, K., and Errington, J. (2009). The cell wall regulator sl specifically suppresses the lethal phenotype of mbl mutants in Bacillus subtilis. J. Bacteriol. 191, 1404-1413.

Schirner, K., Marles-Wright, J., Lewis, R.J., and Errington, J. (2009). Distinct and essential morphogenic functions for wall- and lipo-teichoic acids in Bacillus subtilis. EMBO Journal 28, 830-842.

Schlaeppi, J.M., and Karamata, D. (1982). Cosegregation of cell wall and DNA in Bacillus subtilis. J. Bacteriol. 152, 1231-1240.

Schlaeppi, J.M., Schaefer, O., and Karamata, D. (1985). Cell wall and DNA cosegregation in Bacillus subtilis studied by electron microscope autoradiography. J. Bacteriol. 164, 130-135.

Schleifer, K.H., and Kandler, O. (1972). Peptidoglycan types of bacterial cell walls and their taxonomic implications. Bacteriological Reviews 36, 407-477.

Schneewind, O., and Missiakas, D. (2014). Sec-secretion and sortase-mediated anchoring of proteins in Gram-positive bacteria. Biochimica et Biophysica Acta (BBA) - Molecular Cell Research 1843, 1687-1697.

Sekiguchi, J., Akeo, K., Yamamoto, H., Khasanov, F.K., Alonso, J.C., and Kuroda, A. (1995). Nucleotide sequence and regulation of a new putative cell wall hydrolase gene, cwID, which affects germination in Bacillus subtilis. J. Bacteriol. 177, 5582-5589.

Sham, L.T., Butler, E.K., Lebar, M.D., Kahne, D., Bernhardt, T.G., and Ruiz, N. (2014). Bacterial cell wall. MurJ is the flippase of lipid-linked precursors for peptidoglycan biogenesis. Science 345, 220-222. 
Shieh, P., Siegrist, M.S., Cullen, A.J., and Bertozzi, C.R. (2014). Imaging bacterial peptidoglycan with near-infrared fluorogenic azide probes. Proc Natl Acad Sci U S A 111, 5456-5461.

Shiomi, D., Sakai, M., and Niki, H. (2008). Determination of bacterial rod shape by a novel cytoskeletal membrane protein. EMBO Journal 27, 3081-3091.

Siegel, S.D., Reardon, M.E., and Ton-That, H. (2017). Anchoring of LPXTG-Like Proteins to the Gram-Positive Cell Wall Envelope. In Protein and Sugar Export and Assembly in Gram-positive Bacteria, F. Bagnoli, and R. Rappuoli, eds. (Cham: Springer International Publishing), pp. 159-175.

Siegrist, M.S., Swarts, B.M., Fox, D.M., Lim, S.A., and Bertozzi, C.R. (2015). Illumination of growth, division and secretion by metabolic labeling of the bacterial cell surface. FEMS Microbiol Rev 39, 184-202.

Siegrist, M.S., Whiteside, S., Jewett, J.C., Aditham, A., Cava, F., and Bertozzi, C.R. (2013). (D)-Amino acid chemical reporters reveal peptidoglycan dynamics of an intracellular pathogen. ACS Chem Biol 8, 500-505.

Sjodt, M., Rohs, P.D.A., Gilman, M.S.A., Erlandson, S.C., Zheng, S., Green, A.G., Brock, K.P., Taguchi, A., Kahne, D., Walker, S., et al. (2020). Structural coordination of polymerization and crosslinking by a SEDS-bPBP peptidoglycan synthase complex. Nature Microbiology 5, 813-820.

Slovak, P.M., Wadhams, G.H., and Armitage, J.P. (2005). Localization of MreB in Rhodobacter sphaeroides under conditions causing changes in cell shape and membrane structure. J. Bacteriol. 187, 54-64.

Smith, T.J., Blackman, S.A., and Foster, S.J. (2000). Autolysins of Bacillus subtilis: multiple enzymes with multiple functions. Microbiology 146, 249-262.

Smith, T.J., and Foster, S.J. (1995). Characterization of the involvement of two compensatory autolysins in mother cell lysis during sporulation of Bacillus subtilis 168. J. Bacteriol. 177, 3855-3862.

Soldo, B., Lazarevic, V., Pagni, M., and Karamata, D. (1999). Teichuronic acid operon of Bacillus subtilis 168. Mol. Microbiol. 31, 795-805.

Sowell, M.O., and Buchanan, C.E. (1983). Changes in penicillin-binding proteins during sporulation of Bacillus subtilis. J. Bacteriol. 153, 1331-1337.

Spratt, B.G. (1975). Distinct penicillin-binding proteins involved in the division, elongation and shape of Escherichia coli K-12. Proc. Natl. Acad. Sci. USA 72, 2999-3003.

Straume, D., Piechowiak, K.W., Olsen, S., Stamsås, G.A., Berg, K.H., Kjos, M., Heggenhougen, M.V., Alcorlo, M., Hermoso, J.A., and Håvarstein, L.S. (2020). Class A PBPs have a distinct and unique role in the construction of the pneumococcal cell wall. Proc. Natl. Acad. Sci. USA 117, 6129-6138.

Sung, M.T., Lai, Y.T., Huang, C.Y., Chou, L.Y., Shih, H.W., Cheng, W.C., Wong, C.H., and Ma, C. (2009). Crystal structure of the membrane-bound bifunctional transglycosylase PBP1b from Escherichia coli. Proc. Natl. Acad. Sci. USA 106, 8824-8829.

Swoboda, J.G., Campbell, J., Meredith, T.C., and Walker, S. (2010). Wall Teichoic Acid Function, Biosynthesis, and Inhibition. ChemBioChem 11, 35-45.

Sychantha, D., Little, D.J., Chapman, R.N., Boons, G.J., Robinson, H., Howell, P.L., and Clarke, A.J. (2018). PatB1 is an O-acetyltransferase that decorates secondary cell wall polysaccharides. Nat Chem Biol 14, 79-85. 
Taguchi, A., Welsh, M.A., Marmont, L.S., Lee, W., Sjodt, M., Kruse, A.C., Kahne, D., Bernhardt, T.G., and Walker, S. (2019). FtsW is a peptidoglycan polymerase that is functional only in complex with its cognate penicillin-binding protein. Nat Microbiol 4, 587-594.

Tiyanont, K., Doan, T., Lazarus, M.B., Fang, X., Rudner, D.Z., and Walker, S. (2006). Imaging peptidoglycan biosynthesis in Bacillus subtilis with fluorescent antibiotics. Proc. Natl. Acad. Sci. USA 103, 11033-11038.

Tocheva, E.I., Lopez-Garrido, J., Hughes, H.V., Fredlund, J., Kuru, E., Vannieuwenhze, M.S., Brun, Y.V., Pogliano, K., and Jensen, G.J. (2013). Peptidoglycan transformations during Bacillus subtilis sporulation. Mol Microbiol 88, 673-686.

Todd, J.A., Bone, E.J., and Ellar, D.J. (1985). The sporulation-specific penicillinbinding protein $5 \mathrm{a}$ from Bacillus subtilis is a DD-carboxypeptidase in vitro. Biochemical Journal 230, 825-828.

Todd, J.A., Bone, E.J., Piggot, P.J., and Ellar, D.J. (1983). Differential expression of penicillin-binding protein structural genes during Bacillus subtilis sporulation. FEMS Microbiology Letters 18, 197-202.

Todd, J.A., Roberts, A.N., Johnstone, K., Piggot, P.J., Winter, G., and Ellar, D.J. (1986). Reduced heat resistance of mutant spores after cloning and mutagenesis of the Bacillus subtilis gene encoding penicillin- binding protein 5 . J. Bacteriol. 167, 257-264.

Tol, M.B., Morales Angeles, D., and Scheffers, D.J. (2015). In Vivo Cluster Formation of Nisin and Lipid II Is Correlated with Membrane Depolarization. Antimicrob Agents Chemother 59, 3683-3686.

Trip, E.N., and Scheffers, D.J. (2015). A 1 MDa protein complex containing critical components of the Escherichia coli divisome. Sci Rep 5, 18190.

Tseng, C.L., Chen, J.T., Lin, J.H., Huang, W.Z., and Shaw, G.C. (2011). Genetic evidence for involvement of the alternative sigma factor Sigl in controlling expression of the cell wall hydrolase gene lytE and contribution of LytE to heat survival of Bacillus subtilis. Arch Microbiol 193, 677-685.

Turner, R.D., Ratcliffe, E.C., Wheeler, R., Golestanian, R., Hobbs, J.K., and Foster, S.J. (2010). Peptidoglycan architecture can specify division planes in Staphylococcus aureus. Nature Communications 1, 1-9.

Turner, R.D., Vollmer, W., and Foster, S.J. (2014). Different walls for rods and balls: the diversity of peptidoglycan. Mol Microbiol 91, 862-874.

Typas, A., Banzhaf, M., Gross, C.A., and Vollmer, W. (2012). From the regulation of peptidoglycan synthesis to bacterial growth and morphology. Nat Rev Microbiol 10, 123-136.

Uehara, T., Parzych, K.R., Dinh, T., and Bernhardt, T.G. (2010). Daughter cell separation is controlled by cytokinetic ring-activated cell wall hydrolysis. EMBO Journal 29, 1412-1422.

van Dam, V., Sijbrandi, R., Kol, M., Swiezewska, E., de Kruijff, B., and Breukink, E. (2007). Transmembrane transport of peptidoglycan precursors across model and bacterial membranes. Mol. Microbiol. 64, 1105-1114.

van den Ent, F., Johnson, C.M., Persons, L., de Boer, P., and Löwe, J. (2010). Bacterial actin MreB assembles in complex with cell shape protein RodZ. EMBO Journal 29, 1081-1090. 
van den Ent, F., Leaver, M., Bendezu, F., Errington, J., de Boer, P., and Lowe, J. (2006). Dimeric structure of the cell shape protein MreC and its functional implications. Mol. Microbiol. 62, 1631-1642.

van Heijenoort, J. (2001). Recent advances in the formation of the bacterial peptidoglycan monomer unit. Natural Product Reports 18, 503-519.

van Teeffelen, S., Wang, S., Furchtgott, L., Huang, K.C., Wingreen, N.S., Shaevitz, J.W., and Gitai, Z. (2011). The bacterial actin MreB rotates, and rotation depends on cell-wall assembly. Proc Natl Acad Sci U S A 108, $15822-15827$.

van Teeseling, M.C., Mesman, R.J., Kuru, E., Espaillat, A., Cava, F., Brun, Y.V., VanNieuwenhze, M.S., Kartal, B., and van Niftrik, L. (2015). Anammox Planctomycetes have a peptidoglycan cell wall. Nat Commun 6, 6878.

Varley, A.W., and Stewart, G.C. (1992). The divIVB region of the Bacillus subtilis chromosome encodes homologs of Escherichia coli septum placement (MinCD) and cell shape (MreBCD) determinants. J. Bacteriol. 174, 6729-6742.

Vollmer, W., and Bertsche, U. (2008). Murein (peptidoglycan) structure, architecture and biosynthesis in Escherichia coli. Biochimica et Biophysica Acta 1778, 1714-1734.

Vollmer, W., and Höltje, J.V. (2004). The architecture of the murein (peptidoglycan) in gram-negative bacteria: vertical scaffold or horizontal layer(s)? J. Bacteriol. 186, 5978-5987.

Vollmer, W., Joris, B., Charlier, P., and Foster, S. (2008). Bacterial peptidoglycan (murein) hydrolases. FEMS Microbiology Reviews 32, 259-286.

Vollmer, W., and Seligman, S.J. (2010). Architecture of peptidoglycan: more data and more models. Trends in Microbiology 18, 59-66.

Vollmer, W., von Rechenberg, M., and Höltje, J.V. (1999). Demonstration of molecular interactions between the murein polymerase PBP1B, the lytic transglycosylase MItA, and the scaffolding protein MipA of Escherichia coli. J. Biol. Chem. 274, 6726-6734.

von Rechenberg, M., Ursinus, A., and Holtje, J.V. (1996). Affinity chromatography as a means to study multienzyme complexes involved in murein synthesis. Microbial Drug Resistance 2, 155-157.

Ward, J.B. (1973). The chain length of the glycans in bacterial cell walls. Biochemical Journal 133, 395-398.

Ward, J.B., and Perkins, H.R. (1973). The direction of glycan synthesis in a bacterial peptidoglycan. Biochemical Journal 135, 721-728.

Warth, A.D., and Strominger, J.L. (1969). Structure of the peptidoglycan of bacterial spores: occurrence of the lactam of muramic acid. Proc. Natl. Acad. Sci. USA 64, 528-535.

Warth, A.D., and Strominger, J.L. (1971). Structure of the peptidoglycan from vegetative cell walls of Bacillus subtilis. Biochemistry 10, 4349-4358.

Warth, A.D., and Strominger, J.L. (1972). Structure of the peptidoglycan from spores of Bacillus subtilis. Biochemistry 11, 1389-1396.

Wei, Y., Havasy, T., McPherson, D.C., and Popham, D.L. (2003). Rod shape determination by the Bacillus subtilis Class $B$ penicillin-binding proteins encoded by pbpA and pbpH. J. Bacteriol. 185, 4717-4726. 
Wei, Y., McPherson, D.C., and Popham, D.L. (2004). A mother cell-specific class B penicillin-binding protein, PBP4b, in Bacillus subtilis. J. Bacteriol. 186, 258-261.

Weidel, W., and Pelzer, H. (1964). Bagshaped Macromolecules--a New Outlook on Bacterial Cell Walls. Adv Enzymol Relat Areas Mol Biol 26, 193-232.

Wheeler, R., Turner, R.D., Bailey, R.G., Salamaga, B., Mesnage, S., Mohamad, S.A.S., Hayhurst, E.J., Horsburgh, M., Hobbs, J.K., and Foster, S.J. (2015). Bacterial Cell Enlargement Requires Control of Cell Wall Stiffness Mediated by Peptidoglycan Hydrolases. mBio 6.

White, C.L., Kitich, A., and Gober, J.W. (2010). Positioning cell wall synthetic complexes by the bacterial morphogenetic proteins MreB and MreD. Mol. Microbiol. 76, 616-633.

Wissel, M.C., and Weiss, D.S. (2004). Genetic analysis of the cell division protein Ftsl (PBP3): amino acid substitutions that impair septal localization of Ftsl and recruitment of FtsN. J. Bacteriol. 186, 490-502.

Woldringh, C.L., Huls, P., Pas, E., Brakenhoff, G.J., and Nanninga, N. (1987). Topography of peptidoglycan synthesis during elongation and polar cap formation in a cell division mutant of Escherichia coli MC4100. J. Gen. Microbiol. 133, 575-586.

Wolf, D., Dominguez-Cuevas, P., Daniel, R.A., and Mascher, T. (2012). Cell envelope stress response in cell wall-deficient L-forms of Bacillus subtilis. Antimicrob Agents Chemother 56, 5907-5915.

Wörmann, M.E., Corrigan, R.M., Simpson, P.J., Matthews, S.J., and Gründling, A. (2011). Enzymatic activities and functional interdependencies of Bacillus subtilis lipoteichoic acid synthesis enzymes. Mol. Microbiol. 79, 566-583.

Wright, J., and Heckels, J.E. (1975). The teichuronic acid of cell walls of Bacillus subtilis W23 grown in a chemostat under phosphate limitation. Biochemical Journal 147, 187-189.

Wu, J.J., Schuch, R., and Piggot, P.J. (1992). Characterization of a Bacillus subtilis sporulation operon that includes genes for an RNA polymerase $s$ factor and for a putative DD-carboxypeptidase. J. Bacteriol. 174, 4885-4892.

Yamamoto, H., Kurosawa, S., and Sekiguchi, J. (2003). Localization of the vegetative cell wall hydrolases LytC, LytE, and LytF on the Bacillus subtilis cell surface and stability of these enzymes to cell wall-bound or extracellular proteases. J Bacteriol 185, 6666-6677.

Yamamoto, H., Miyake, Y., Hisaoka, M., Kurosawa, S., and Sekiguchi, J. (2008). The major and minor wall teichoic acids prevent the sidewall localization of vegetative DL-endopeptidase LytF in Bacillus subtilis. Mol Microbiol 70, 297-310.

Yang, D.C., Peters, N.T., Parzych, K.R., Uehara, T., Markovski, M., and Bernhardt, T.G. (2011). An ATP-binding cassette transporter-like complex governs cell-wall hydrolysis at the bacterial cytokinetic ring. Proc. Natl. Acad. Sci. USA 108, E1052-1060.

Yanouri, A., Daniel, R.A., Errington, J., and Buchanan, C.E. (1993). Cloning and sequencing of the cell division gene $\mathrm{pbpB}$, which encodes penicillin-binding protein 2B in Bacillus subtilis. J. Bacteriol. 175, 7604-7616. 
Yu, Y., Zhou, J., Dempwolff, F., Baker, J.D., Kearns, D.B., and Jacobson, S.C. (2020). The Min System Disassembles FtsZ Foci and Inhibits Polar Peptidoglycan Remodeling in Bacillus subtilis. mBio 11, e03197-03119.

Yuan, Y., Barrett, D., Zhang, Y., Kahne, D., Sliz, P., and Walker, S. (2007). Crystal structure of a peptidoglycan glycosyltransferase suggests a model for processive glycan chain synthesis. Proc. Natl. Acad. Sci. USA 104, 5348-5353.

Yunck, R., Cho, H., and Bernhardt, T.G. (2016). Identification of MltG as a potential terminase for peptidoglycan polymerization in bacteria. Mol Microbiol 99, 700-718.

Zellmeier, S., Zuber, U., Schumann, W., and Wiegert, T. (2003). The absence of Fts $\mathrm{H}$ metalloprotease activity causes overexpression of the sW-controlled pbpE gene, resulting in filamentous growth of Bacillus subtilis. J. Bacteriol. 185, 973-982.

Zhang, Y.H., Ginsberg, C., Yuan, Y., and Walker, S. (2006). Acceptor substrate selectivity and kinetic mechanism of Bacillus subtilis TagA. Biochemistry 45, 10895-10904.

Zheng, S., Sham, L.T., Rubino, F.A., Brock, K.P., Robins, W.P., Mekalanos, J.J., Marks, D.S., Bernhardt, T.G., and Kruse, A.C. (2018). Structure and mutagenic analysis of the lipid II flippase MurJ from Escherichia coli. Proc Natl Acad Sci U S A 115, 6709-6714.

Zielińska, A., Savietto, A., de SoUSA Borges, A., Martinez, D., Berbon, M., Roelofsen, J.R., Hartman, A.M., de Boer, R., Van der Klei, I.J., Hirsch, A.K.H., et al. (2020). Flotillin-mediated membrane fluidity controls peptidoglycan synthesis and MreB movement. eLife 9, e57179.

Zuber, B., Chami, M., Houssin, C., Dubochet, J., Griffiths, G., and Daffe, M. (2008). Direct visualization of the outer membrane of mycobacteria and corynebacteria in their native state. J. Bacteriol. 190, 5672-5680. 
